$8-17-2013$

\title{
The Efficacy of Repeated Reading on Secondary Students' Oral Reading Fluency and Retell Fluency
}

Cynthia S. Driggs

Cedarville University

Follow this and additional works at: http://digitalcommons.cedarville.edu/education_theses

Part of the Educational Assessment, Evaluation, and Research Commons

\section{Recommended Citation}

Driggs, Cynthia S., "The Efficacy of Repeated Reading on Secondary Students' Oral Reading Fluency and Retell Fluency" (2013). Master of Education Research Theses. 61.

http://digitalcommons.cedarville.edu/education_theses/61 


\section{The Efficacy of Repeated Reading on Secondary Students' \\ Oral Reading Fluency and Retell Fluency}

A thesis submitted in partial fulfillment of the requirements for the degree of

Masters of Education

By

Cynthia S. Driggs

B.S. Physical Education and Health, Taylor University 1983

Reading Endorsement, Ohio University 2005

2013

Cedarville University 


\title{
THE EFFICACY OF REPEATED READING
}

\begin{abstract}
Driggs, Cynthia S. M.Ed., Education Department, Cedarville University, 2013. The Efficacy of Repeated Reading on Secondary Students' Oral Fluency Rate and Retell Rate.
\end{abstract}

Today's secondary students need effective reading instruction in order to meet the demands of The College and Career Readiness Standards. Since fluency and comprehension comprise essential components of effective reading instruction, this quantitative research is a controlled experiment with a pretest-posttest control-group design. The questions asked include the following: (a) Does repeated reading improve secondary students' oral reading fluency as measured by increase in the number of words read per minute?

(b) Does repeated reading improve secondary students' retell fluency as measured by increase in the number of words retold from the passage? An experimental group that received interventions and a control group that did not receive interventions were administered pretest and a posttest. The results of an independent samples $t$-test indicated repeated reading had a significant effect on oral reading fluency $t(30)=4.12, p .<.001$ and retell fluency $t(30)=4.58, p .<.001$. 


\section{TABLE OF CONTENTS}

\section{Page}

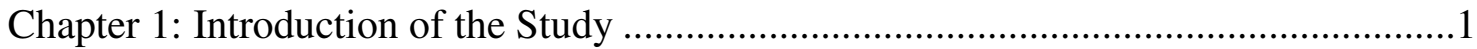

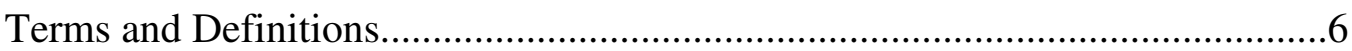

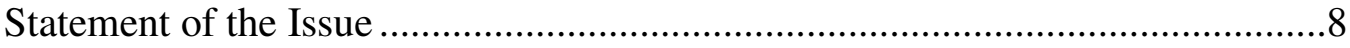

Scope of Study and Delimitations........................................................ 10

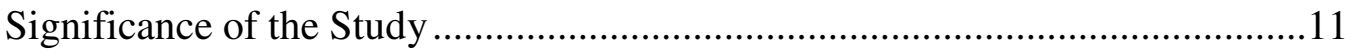

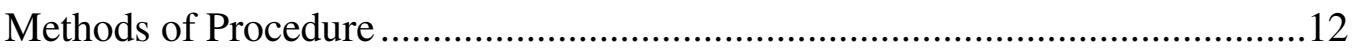

Chapter 2: Literature Review ................................................................... 14

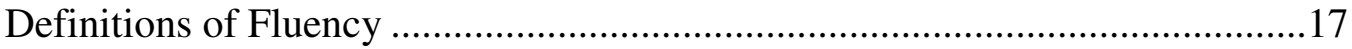

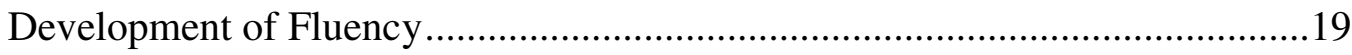

Fluency's Correlation to Comprehension ....................................................24

Methods to Increase Fluency... .............................................................29

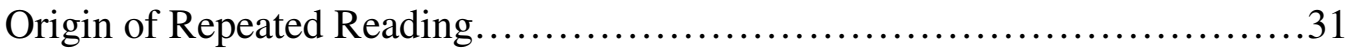

Measuring Fluency and Comprehension..................................33

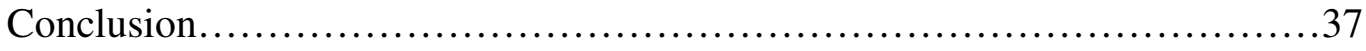

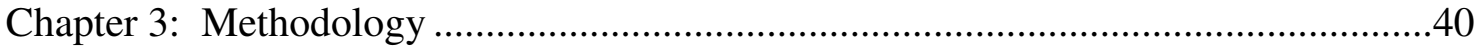

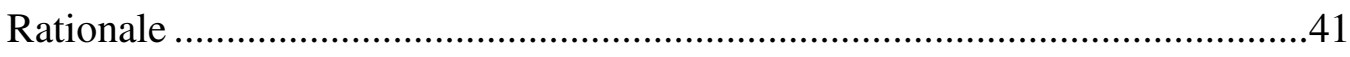

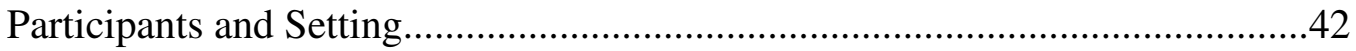

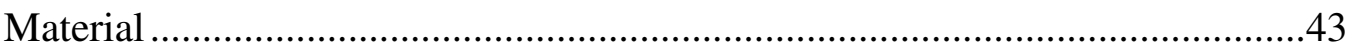

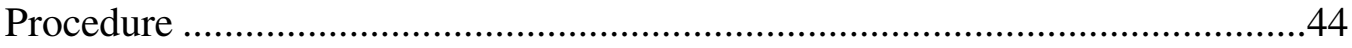




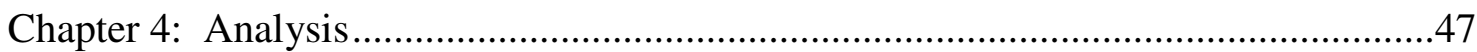

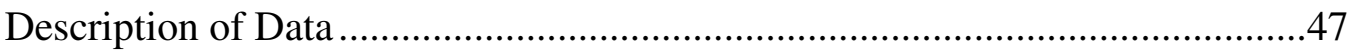

Data Analysis ......................................................................................4 48

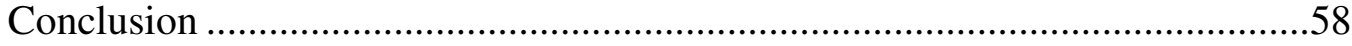

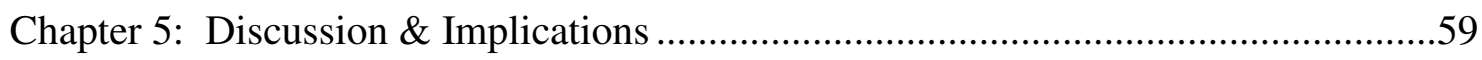

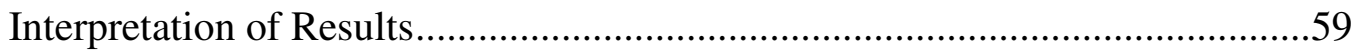

Potential Applications of the Findings......................................................60

Biblical Integrative Component ............................................................62

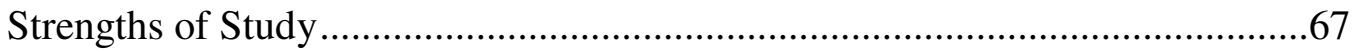

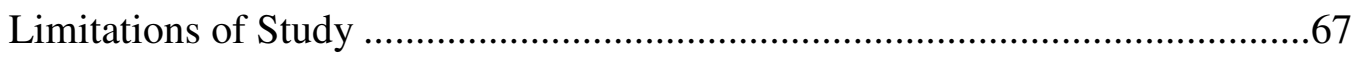

Suggestions for Further Research ....................................................6

References.........................................................69

Appendices............................................................... 76 


\section{Chapter 1: Introduction of the Study}

During the past decade in the field of literacy education, researchers and educators have encountered a major shift in the role of fluency. Fluency has transformed from a rarely encountered instructional component into driving major curriculum decisions (Kuhn, Schwanenflugel, Meisinger, Levy, \& Rasinski, 2010). Hudson and colleagues agreed that fluency has gained new significance as a crucial component of every reading program, especially for students who struggle in reading (Hudson, Pullen, Lane, \& Torgesen, 2009). Klauda and Guthrie (2008) also suggested that both the individual components of fluency and their relationship to comprehension have recently gained attention. Similarly, Rasinski (2012), a leading professor in the field of reading and fluency, declared that fluency should be a "hot topic" (Rasinski, 2012, p. 517) for teachers and experts of reading because of fluency's close link to comprehension.

Nichols, Rupley, and Rasinski (2009) explained the importance of fluency and its link to comprehension in the following statement:

The ability to understand and react to ideas expressed in writing is the essence of reading, and if we accept that the ultimate goal of reading is comprehension and learning from text, it is important for teachers to understand how fluency is the essential component that nurtures and brings about this capability. (p. 3)

When students can identify words automatically and accurately, they can comprehend much more easily because their cognitive resources are free to make meaning. Hence, researchers and educators have witnessed fluency's rise to prominence in the reading world because of its importance to overall reading health. 
Although fluency has recently gained significance, Murray, Munger, and Clonan (2012) found the data verify that fluency may not be developing as it should (Murray et al., 2012). Other researchers have also uncovered alarming news about the foundational skills of secondary students. Paige, Rasinski, and Magpuri-Lavell (2012) declared that "we face a crisis in the United States concerning the literacy development of secondary students" (p. 73). For instance, the National Assessment of Educational Progress disclosed that only 35 percent of eighth-grade students scored at or above The Proficient level in reading (NAEP; National Center for Education Statistics, 2009). This statistic means that almost two-thirds of eighth grade students scored the proficient. Of this group that scored below proficient, the study revealed that 38.5\% scored below Basic (Paige, et al., 2012). Roberts and colleagues added insight into these scores when they defined below Basic as "unable to understand important concepts and acquire new knowledge from grade-level-texts" (Roberts, Torgesen, Boardman, \& Scammacca, 2008, p. 63). According to these statistics, students entering high school may lack basic reading skills. In light of these statistics, today's educators should be particularly alarmed about basic reading skills because in recent years, extensive research has established the need for college and career ready students to be proficient in independently reading complex informational content area text (Common Core State Standard Initiative, 2012). Educators expect twenty-first century students to read and comprehend at a very complex level. For instance, since Ohio and many other states have adopted, or are in the process of adopting, the Common Core State Standards for College and Career Readiness (CCSS), secondary students must possess basic, essential reading skills that allow them to read at ever increasingly complex level. Students must demonstrate independence and a 
wide-knowledge base. They must also show the ability to cite evidence to demonstrate understanding; evaluate the author's purpose, tone, and subtle nuances; critique, evaluate, and synthesize information (Common Core State Standard Initiative, 2012). Students need comprehension in order to apply higher level thinking skills such as, evaluation, synthesis, and construction. Students must develop these skills demanded by the Common Core State Standards.

To meet these standards, Hiebert and Pearson (2012) found that schools all over the United States are altering curriculum at all grade levels to meet the demands for higher expectations in reading and writing. As important Common Core State Standards curricular changes are made, Hiebert and Pearson (2012) also cautioned educators to remember that foundational skills must be mastered before advanced skills. They insisted educators remember that students need underlying, basic skills "as we move into the Common Core era, in which deeper learning and more advanced literacy assume a prominent role" (Hiebert \& Pearson, 2012, p. 48). Most literacy educators considered fluency to be one of these basic underlying skills of reading development (Kuhn et al. 2010). Without the basic reading skills, students will struggle to meet all these complex expectations. As has previously been stated, fluency emerges as a critical skill because of its correlation to comprehension.

Educators and researchers have had difficulty coming up with one definition of fluency. The 2004 National Reading Panel Report stated, "Oral reading fluency is the ability to read text aloud with accuracy, speed, and proper expression" (Shanahan, 2006, p. 18). The three components that work together to bring about fluency, according to Nichols et al. (2009), include "accuracy of recognition, automaticity of word recognition, 
and reading orally with appropriate prosodic features such as expression, stress, pitch and suitable phrasing” (p. 3). Kostewicz (2012) defined fluency as reading speed and accuracy so that teachers would have a clear, measureable definition. While this concise definition does not include prosody and word recognition automaticity like others such as Kuhn et al. (2010) and Therrien, Kirk, and Woods-Groves (2012), teachers can easily determine what to measure when they focus on the number of words read correctly in a certain amount of time. For the purpose of this research, I have measured oral reading fluency according to Kostewicz's (2012) definition of reading speed and accuracy. Ari (2011) stated that "fluency is usually measured as number of words read correctly (orally or silently) per minute," (p. 6) or to put it another way, correct words read per minute (CWPM). When a students' fluency is measured as they read aloud, it is referred to as Oral Reading Fluency (ORF). ORF will be used as the preferred method to measure CWPM.

Researchers encouraged caution when concentrating on evaluating students reading skills purely on speed and CWPM. They worried that students will begin to view reading as simply speed-reading. Rasinski (2012) disliked the idea of fluency instruction that only focuses on speed because he believed fluency included reading for meaning. He felt so strongly about reading for speed without meaning that he called it "wrong" (Rasinski, 2012, p. 517). To avoid students purely reading for speed, Samuels (2006) advocated giving a student a task that required decoding and comprehension at the same time. He suggested a story retell (Samuels, 2006). Therefore, I have included the retelling component in this research so that students do not solely focus on speed. 
Teachers can develop students' fluency with proper instructional methods. Students who struggled in reading as well as those students who fell within the typical range of reading abilities experienced positive benefits from fluency instruction (Shanahan, 2006). Kostewicz (2012) proclaimed that educators now have a formula for reading success in the implementation of systematic, guided oral reading fluency practice for students called repeated reading (RR). The RR method refers to the deliberate practice in which a student repeatedly reads a grade level passage until a set correct word per minute (CWPM) goal has been reached. The students read a passage at their independent or instructional grade-level. Otherwise, the reading passage will be too difficult for students to read fluently. When implementing the RR method, educators can vary certain aspects of the method, such as the amount of time students read, the process of correcting errors, the manner of performance feedback and progress monitoring, and the acceptable goal (Kostewicz, 2012). Hence, many researchers have recommended RR with its various versions as one way to develop fluency.

I would like to explore the RR fluency developing method with secondary students due to a lack of research at this level. For example, researchers have conducted many studies on fluency and RR, but most of these studies have been conducted at the elementary level. Educators and researchers seem to find little research on effective reading fluency practices for struggling secondary readers. For example, Wexler, Vaughn, Roberts, and Denton (2010) concluded that from 1980-2005 only 19 studies, six of which were empirical studies, were conducted on fluency intervention for struggling readers in sixth through twelfth grade. Moreover, Rasinski, Rikli, and Johnston (2009) 
suggested the need for more research at the middle and secondary school level, especially for those students who are struggling to reach today's levels of literary competency.

One of the goals of this research is to add to the limited amount of research literature on the efficacy of RR on students at the secondary level. Additionally, I would like to determine if the RR method with a retell component would benefit the content area curriculum as an activity to improve fluency and comprehension in the secondary classroom. More specifically, I would like to explore the benefit of RR to secondary students' fluency and its link to comprehension. These two pillars of effective reading instruction have great significance for students at the secondary level. Therefore, the two questions that this research would like to explore include the following:

(a) Does repeated reading improve secondary student's oral reading fluency as measured by an increase in the number of words read per minute?

(b) Does repeated reading improve secondary student's comprehension as measured by the number of words retold from the passage?

\section{Terms and Definitions}

Accuracy. This refers to the reader's ability to read an author's words without deviation (Shanahan, 2006).

Automaticity. This refers to the reader's ability to recognize words automatically or effortlessly (Rasinski, 2012).

CBM/ORF. This most common method for assessing reading fluency is frequently referred to as Curriculum-Based Measurement/Oral Reading Fluency (CBM/ORF). This measures the number of words read correctly in one minute (Hudson et al., 2009). 
CWPM. A scoring procedure used in RR to determine the correct number of words read in one minute. The score is calculated by subtracting the total number of words read by the number of errors (Kostewicz, 2012).

Deep Reading. This is also known as RR in which a student is asked to read a single text repeatedly until a level of fluency is achieved (Rasinski, 2012).

Errors. "a. omissions (i.e., student failed to attempt to pronounce a word and moved onto the next word on the page; b. substitutions (i.e., the student pronounced a word that bore no phonemic relationship to the printed word, e.g. 'pond' for 'lake'); c.

mispronunciations (i.e., the student failed to pronounce part of the printed word correctly); d. Reversals (i.e., the student read words in the sentence in incorrect sequence, e.g., 'There once was a dog' for 'Once there was a dog'); and e. additions (i.e., words were added to the text which originally were not there, e.g., 'the little girl' for 'the girl' (Marchand-Martella, Martella, Orlob, \& Ebey, 2010, p. 8).

Fluency. In this study fluency was defined as a student's reading rate (Kostewicz, 2012); "the ability to read with speed, accuracy and proper expression" (Lo, Cooke, \& Starling, 2011, p. 115); "the ability to simultaneously process written texts accurately, automatically, with appropriate prosody and comprehension" (Rasinski, Samuels, Hiebert, Petscher, \& Feller, 2011 p. 76).

Non transfer passage. These are passages that students practice multiple times during RR sessions (Lo et al., 2011).

ORF. This is an abbreviation for oral reading fluency (Bellinger \& DiPerna, 2011); a reader's ability to read text aloud with accuracy, speed, and proper expression (Shanahan, 2006). 
Prosody. A reader's ability to read with appropriate expression or intonation coupled with phrasing that allows for the maintenance of meaning (Kuhn et al., 2010).

Repeated Reading. Repeated reading involves asking a student to reread a specific passage out loud several times, while the teacher or partner records the number of words read correctly per minute. A goal may be set for the student to reach a certain number of words correct per minute. RR may also provide some means of feedback to monitor student progress (Lo et al., 2011).

RTF. This is the abbreviation for retell fluency task in which the number of words recalled from the passage in one minute is scored to assess comprehension (Bellinger \& DiPerna, 2011)

Self correction. The reader's spontaneous correction of an error without verbal or nonverbal prompting by instructor or peer tutor that are not counted as errors (MarchandMartella et al., 2010).

Transfer passage. Students read a new passage that they have not previously read (Lo et al., 2011).

Wide Reading. Students read a text once followed by discussion, response, and instruction with the goal of developing specific reading strategies; this procedure is repeated many times with a different text each time (Rasinski, 2012).

\section{Statement of the Issue}

Kostewicz (2012) asserted that the educational world has promoted reading fluency into the limelight because the ability to read fluently has becomes a measure of students' overall reading health. Students with proficient fluency demonstrate reading health partially because of comprehension's close correlation to fluency. For instance, Bellinger and DiPerna (2011) confirmed the correlation between fluency and 
comprehension when they stated, "Oral Reading Fluency (ORF) has demonstrated strong relationships $(.60<r<.90)$ with reading comprehension" (p. 417). Researchers gave evidence that some middle school and high school students, however, lack the reading fluency skills they need to be successful. For instance, Paige et al. (2012) found in their study that students' poor silent and ORF was significantly correlated to poor comprehension among ninth grade readers. Rasinski et al. (2009) found when measuring fluency by reading rates, "a significant number of ninth grades students read at rates that were well below the norms expected of eighth graders" (p. 351). Moreover, secondary students encountered problems developing fluency because teachers stop emphasizing ORF after elementary school (Paige et al., 2012) Kostewicz (2012) proposed even though fluency's development in the classroom has been established as important, and perhaps one of the most important academic skills, it has not been given the needed focus in the classroom.

When the National Reading Panel examined studies of ORF instruction, they "found a substantial pattern of evidence supporting the idea that teaching oral reading fluency improves reading achievement" (Shanahan, 2006, p. 18). They also found that quality fluency instruction must include oral reading, repetition, and guidance or feedback (Shanahan, 2006). The method of RR meets all of these requirements. Kostewicz (2012) also declared that RR can help teachers with the overwhelming task of individualizing reading fluency instruction while utilizing the resources on hand.

Since students seem to benefit from RR, the purpose of this research includes evaluating the efficacy of RR on secondary students ORF and RTF. This will add to the 
limited literature that is available on this topic at the high school level and also determine the value of this strategy for future use in secondary classrooms to develop fluency.

\section{Scope of the Study and Delimitations}

The setting of this study was a school district in the south central part of Ohio, which served approximately 2,166 students. This study was conducted at the high school, which served 559 students-281 males and 278 females. About $45 \%$ of the students are eligible for the free and reduced lunch program. Ninety-three percent of the student population is Caucasian.

Thirty-two secondary students, who attend this high school, were randomly slected to participate in this experiment. A proportional number of male and female students from each grade of the four grade levels were chosen through proportional stratified sampling. The study focused on high school students because of the lack of research on RR at this level. I also focused on this level to determine average fluency reading rate of students at this high school. This information could demonstrate the need for additional research or changes and additions to the current curriculum in both content area reading and in language arts reading. Secondly, the sample size was limited to 32 students because I did not have the resources to accurately and reliably conduct a larger study. Additionally, some aspects of the treatment condition such as error correction, word preview, prosody evaluation, and vocabulary components were left out due to lack of instructional resources and time. The students volunteered to participate in the testing. The students participated in intervention treatments in the morning, after school, or during their study hall period. Finally, RTF was also implemented to assess comprehension rather than using comprehension questions or units of meaning. With 
limited trained instructors, students' paired CWPM scores in ORF and RTF during the intervention treatments were used as a progress monitoring component. Students also graphed their scores to monitor their progress.

\section{Significance of the study}

Marchand-Martella et al. (2010) asserted many of today's middle school and high school students lack basic reading skills to keep pace with their classmates. Hudson et al. (2009) declared that if the decoding process is not fluent, reading passages with unfamiliar words can be exhausting and exasperating. Bellinger and DiPerna (2011) mentioned that "children with poor comprehension skills are at risk for educational obstacles" (p. 416). These reading deficiencies lead to tumultuous affects on students' education. McComas and colleagues supported the seriousness of reading proficiently as they state, "individuals who do not learn to read proficiently experience poor postsecondary education outcomes, difficulties gaining and sustaining employment, and incarceration" (McComas et al., 2009, pp.56-57). Students, who struggle in fluency, oftentimes struggle in comprehension. Hence, low fluency and comprehension levels at the secondary level can create compounding academic problems for students.

Lo et al. (2011) concluded that RR, which has been researched for decades with successful outcomes, is a practice that has the ability to improve reading fluency. Additionally, Reutzel, Jones, Fawson, and Smith (2008) felt that guided repeated oral reading is an "established scientifically supported reading fluency practice approach that the National Reading Panel highly recommends" (p. 39). During this practice, a student reads a single instructional level passage three to five times receiving feedback from a teacher or student mentor (Reutzel et al., 2008). The student should improve the fluency 
and accuracy score with each reading as material becomes more familiar. Finally, Paige et al. (2012) also endorsed RR at the secondary level, particularly for students who struggle with reading comprehension and fluency.

The significance of this research includes determining if RR is an effective way to aid in the development of secondary student's ORF because the correlation between fluency and comprehension appears to be high. Furthermore, since fluency seems so closely linked to comprehension, not only will students be able to increase fluency, but comprehension could be enhanced at the same time. If this study can give evidence for the effectiveness of RR, then this procedure could be encouraged for use in content area classrooms as well as literature-based classrooms to increase fluency and comprehension.

\section{Methods of Procedure}

In this quantitative study, I collected data on the student's pretest and posttest oral fluency reading (ORF) rates of the eighth grade benchmark CBM passages from AIMSweb using the correct words per minute (CWPM) method with a control group and an experimental group. As a comprehension component, an oral story-based retell fluency task (RTF) was scored. This task required students to retell as much of the story as they could recall in one minute. The experimental group received 12 to 14 treatments over the course of a 3 week period. The pretest and posttest mean difference of each group was assessed. Next, I conducted an independent samples $t$ test using the differences of the mean average ORF and RTF scores between the RR experimental group and the control group.

Research questions: 
(a) Does repeated one minute reading of instructional level reading passages improve ORF as measured by increase in the number of correct words read per minute ?

(b) Does repeated one minute reading of instructional level reading passages with a retell activity improve RTF as measured by the number of words retold from the reading passage?

Null hypothesis one states that RR does not produce a difference in ORF scores between a group of students that practice RR and those that do not practice RR. The alternative hypothesis is that the group that uses RR will score higher on the oral reading fluency than the group that does not. Furthermore, the null hypothesis two states that that RR does not produce a difference in RTF scores between groups of students that practice $\mathrm{RR}$ and those that do not practice RR. The alternative hypothesis is that the group that uses RR will have a RTF score higher than the group that does not. 


\section{Chapter 2: Literature Review}

As has already been stated, educators and researchers have witnessed an important swing in fluency's role in the literacy curriculum during the past 10 years shifting from a seldom-utilized instructional element to one dictating critical instructional choices. Nichols et al. (2009) claimed the research has provided teachers with effective strategies for developing fluent readers. In spite of recent emphasis on fluency and increased fluency strategies, students who lack literacy development, including fluency, are a national concern (Paige et al., 2012). They state that the "evidence strongly suggests that significant numbers of high school students are not achieving at an elevated level in an environment that demands increasingly expanded literacy skills" (Paige et al., 2012, p. 73). More specifically, in secondary schools, such as the one where they conducted their study, Paige et al. (2012) found "a significant number of students with poorly developed fluency" (p. 71). Hence, the evidence seems to indicate that secondary students need instruction to develop fluency along with other literacy skills, such as comprehension.

The researchers claimed, however, that secondary educators have not given fluency the attention that it deserves. Wexler et al. (2010) claim that middle school and high school fluency instruction merits further attention. For example, they found that over the past ten years, law makers and educational experts have promoted early intervention to prevent reading disabilities in young children, but have not been as concerned with reading disabilities of older students (Wexler et al., 2010). They claimed that, "considerably less attention has been provided to remediating reading difficulties at the secondary level" (Wexler et al., p. 2). Moreover, a recent study found $40 \%$ of U.S. 
fourth grade students were not fluent readers (Begney, Krouse, Ross, \& Mitchell, 2009).

One explanation for this problem conceded that after third grade, teachers no longer stressed or developed fluency because they no longer plan oral reading instruction. Silent reading appears to make up the bulk of elementary reading instruction after third grade. Paige et al. (2012) asked an important question, "If fluency is not a priority in the primary grades, why should it be a priority in later grades?” (p. 74). Students who lack fluency in third grade receive little to no instruction or opportunity to improve throughout the rest of their educational years (Paige et al., 2012). Additionally, Ardoin, Eckert, and Cole (2007) also cited statistics similar to Begney et al. (2009) that $40 \%$ of students were "nonfluent readers" (p. 56). Using the premise stated earlier, "that these fourth-grade students are unlikely to receive instruction to correct this problem," $40 \%$ of high school students might graduate as non-fluent readers.

Researchers have found other reasons secondary students may lack fluency. First, they proclaimed that if fluency is practiced, it is usually practiced as an isolated skill; students experience difficulty transferring this skill into everyday reading without explicit modeling and instruction on how to do this (Paige et al., 2012). Second, an expanding body of research has challenged three misconceptions about fluency (Paige et al., 2012). Misconception number one stated that fluency should be mastered in the early stages of reading. This is a misconception because students, who struggle in the primary grades with word automaticity, still need fluency instruction after their early stages of fluency even though their peers may not. Misconception number two stated that by upperelementary grades and above fluency should not be a major concern for most readers. Again, the statistic previously stated that $40 \%$ of fourth grade students are not fluent 
readers (Begney et al., 2012) dispels this myth. Misconception number three stated that by "secondary grades, fluency instruction should be minimized, if offered at all" (Paige et al. 2012, p. 68). The authors propose that these misconceptions have undermined fluency's importance in high school instruction so that it has not been given priority in the secondary curriculum.

What happens when fluency is not given the priority it deserves in the high school curriculum? Secondary students who have reading difficulty may take longer than their classmates to accurately decode text (Hawkins, Hale, Sheeley, \& Ling, 2011). Rasinski (2012) suggested those slow readers' frustration and lack of interest in reading increases in middle and high school reading when assignments of 30 to 60 minutes become assignments that call for 90 to 180 minutes because of students' lack of reading automaticity. He believed their extremely slow reading rates necessitate two to three times more time to complete assignments than readers with more fluency (Rasinski, 2012). Wexler et al. (2010) also concurred with Rasinski's findings that secondary students are challenged to keep up with complex content at a pace that is faster than their skills allow. Students who find reading tiresome are less likely to read outside of school. At the same time, however, their more proficient classmates are enriching their reading skills. Consequently, those who read little because they are not fluent, miss out on limitless opportunities to practice reading, while their fluent peers continue to improve. Stanovich (2008) referred to this as the "rich-get-richer and poor-get-poorer pattern of reading achievement" (p. 23). Often this pattern starts very early in students' careers and increases as their frustrations mount over not being able to keep pace. This can lead to lack of basic reading skills and academic failure in later years. 
Not only have researchers demonstrated that fluency is a significant variable in secondary students reading and overall academic studies, research has also revealed correlation between fluency and comprehension (Bellinger \& DiPerna, 2011). For example, Paige et al. (2012) claimed that "research has shown that automaticity in the word-recognition component of fluency, as measured by reading rate, is strongly associated with good comprehension at the secondary grades" (p. 69). Consequently, student comprehension seems to require fluency. The connection between fluency and comprehension will be examined in more detail later.

With this recent scholarly emphasis on fluency, in contrast to rank-and-file teachers' seeming lack of attention to fluency's development, educators may find a comprehensive understanding of fluency, especially at the secondary level, very beneficial. Therefore, in this study, I will examine the definition of fluency, its development, and its correlation to comprehension.

\section{Definitions of Fluency}

Researchers have experienced difficulty agreeing on a common definition of fluency. Bellinger and DiPerna (2011) claimed that "there is no universally accepted definition of fluency" (p. 417). Consequently, I will examine the multiple definitions of fluency. Previously mentioned, the National Reading Panel Report defined oral reading fluency as "the ability to read text aloud with speed, accuracy, and proper expression" (Shanahan, 2006, p. 18). Gorsuch and Taguchi (2010) further defined fluency as decoding of text that is done effortlessly and efficiently so that the text can be read orally or silently with appropriate comprehension, phrasing, and expression. Some researchers simply declared fluency is the opposite of slow, choppy, or hesitant reading. Perhaps 
students in a second grade classroom created the simplest all-encompassing definition of fluency. They defined it as "reading like you talk, not too fast and not too slow, with expression and no sounding out. It's also important to understand what you read" (Cahill \& Gregory, 2011, p.128).

Kuhn et al. (2010) suggested that even though the many definitions of reading fluency stress its various components, "there seems to be a growing consensus that accuracy, automaticity and prosody all make a contribution to the construct" (p. 231). These researchers seemed to agree that fluency can be viewed as accuracy and automaticity (Kuhn et al., 2010). They felt, however, that an undue emphasis has been placed on accuracy and automaticity because they are the "most quantifiable elements of fluency" (Kuhn et al., 2010, p. 239). This over emphasis on accuracy and automaticity results in neglect of fluency's other aspects such as phrasing, appropriate pacing, and intonation. Thus, Kuhn et al. (2010) recommended the following all-inclusive definition: Fluency combines accuracy, automaticity and oral reading prosody, which, taken together facilitate the reader's construction of meaning. It is demonstrated during oral reading through ease of word recognition, appropriate pacing, phrasing, and intonation. It is a factor in oral and silent reading that can limit or support comprehension. (p. 240)

These scholars felt the valor of this definition included its ability to highlight the relationship between fluency and comprehension, to emphasize prosody and accurate and automatic word recognition, and to address the role of fluency in silent and oral reading (Kuhn et al., 2010). 
Furthermore, Paige et al. (2012) suggested "fluency is automatic word recognition that is most often measured through reading speed" (p. 68), but stressed that fluency is not just speed-reading. Kostewicz (2012) also liked a measureable definition of ORF when he defined it as speed and accuracy. Vadasy and Sanders (2008) also agreed with Kostewicz's definition. With this concise definition, a teacher can quickly make a determination of what to measure by concentrating on words read correctly and incorrectly in a set amount of time (Kostewicz 2012). Ari (2011) stated that "fluency is usually measured as number of words read correctly (orally or silently) per minute" (p. 6) or as correct words read per minute (CWPM). In this research, I use these researchers' definition that fluency can be measured through rate or speed. Educators can measure a students' fluency when they read aloud; this is referred to as oral reading fluency (ORF). I will use the ORF method as the preferred method to measure CWPM.

\section{Development of fluency}

Some researchers and reading scholars believe the development of fluency consists of two parts, while others believe it consists of multiple parts. For instance, Paige and constituents believed that fluency consists of two key components (Paige et al., 2012). The first component consists of word recognition automaticity, which is the capacity to recognize words in text so effortlessly that a reader can concentrate on the more important job of making meaning. Samuels, (2006) developed this model of automatic processing with LaBerge. One of the main premises of this bottom-up information processing model concluded that if students have to use most of their cognitive energy to decode the words in a passage, they have very little energy left to comprehend, which is the most important task in reading (Rasinski, 2012). The bottom- 
up model meant that the "sequence of events in reading starts from the bottom with the letters and the words, and then the flow of information moves up to meaning" (Samuels, 2006, p. 335).

Gorsuch and Taguchi (2010) expanded this idea as they discuss the difference between lower-level and higher-level comprehension processes. They felt the lowerlevel processes, which allow word recognition, are comprised of "letter feature extraction, orthographic segmentation, and phonological coding" (Gorsuch \& Taguchi, 2010, p. 32). Higher level processes, which they call post-lexical access, included comprehension of larger chunks of information such as sentences, paragraphs, and entire passages. Fluent readers used both processes. The heart of fluency appears to be automaticity of reading words so that attention is freed to attend to meaning. Hence, these researchers concluded that when readers can recognize words automatically, their cognitive resources are free to engage in higher-level processes (Gorsuch and Taguchi, 2010; Rasinski, 2012; Samuels, 2006).

The second part of fluency consists of prosody or reading with appropriate expression or intonation coupled with phrasing that allows for the maintenance of meaning. This slowing down, speeding up, raising and lowering pitch and volume, pausing, and emphasizing certain syllables augments textual comprehension. Rasinski et al. (2009) made this definition even clearer as he compared it to speaking in that speakers convey meaning by their rate, pitch, stress and phrasing. Fluent readers do the same thing with their voices in reading to also convey meaning. In other words, a reader who reads with prosody makes reading aloud sound like spoken language (Rasinski, et al. 2009). This research recognizes prosody as component of fluency. However, since 
Hudson et al. (2009) suggested that prosody will be hard to measure until reliable and efficient scales are developed, it will not be measured in this research project.

Nichols et al. (2009) found that many reading researchers support Jean Chall's developmental view of reading. This foundational developmental view recognizes the crucial instructional components of teaching reading in order as they are developed. For instance, she listed the major qualitative reading abilities from preschool through college. She described the stages as overlapping and not specifically fixed. For example, a second grader could be in Stage 3, while a seventh grader could be in Stage 1. The stage could also vary according to the level of the text. Knowledge of these stages can be helpful in understanding when and how fluency and comprehension begin to develop. Nichols et al. (2009) explain Chall's stages of reading development that can assist educators in their quest to develop student's fluency. The first three stages described contain a brief summary of Chall's stages of development from the work of Nichols et al, (2009).

In Stage 0, students begin to use contextual or logographic information and the predictable language of the text in order make guesses or predictions about the words they are attempting to read. Learners grow in their understanding of how semantic and syntactic language functions in the world around them. Children use three contextual means of information-pictures, predictable language of texts, and stories that mimic spoken language. Throughout this stage, readers also use logographic information to make predictions about the words. For example, symbols similar to McDonald's golden arches or Nike's swish provide information to make guesses about words (Nichols et al, 2009). This stage also has a very general understanding of phonological awareness such 
as identifying and creating words that rhyme and becoming aware that words are made up of beginning and ending sounds.

In Stage 1, students learn language awareness, phonological insights and word recognition. Phonological awareness broadens so that students can recognize rimes and onsets along with phonics. The alphabetical principle is critical in this stage as readers are attempting to crack the code of print. In order to do this, they must realize that letters and letter combinations represent sounds of language, which Nichols et al. (2009) cite as a prerequisite to fluency. Hence, systematic and direct phonics instruction is a critical part of reading instruction in this stage.

In Stage 2, students develop into fluid readers that can automatically and accurately decode words. Mastery of this stage, frees up a reader's attention for higher levels of comprehension and meaning. Furthermore, progress in this stage means that readers develop the "ability to connect words with their background knowledge and focus on chunking the ideas represented" (Nichols et al., 2009, p. 2). Successful completion of learning to read phase produces a fluid reader who automatically and accurately decodes words. This frees a reader's attention to make meaning. In this stage readers need plenty of practice with comfortable levels of text in order to fine tune their reading skills. Educators must provide crucial fluent reading instruction at this stage. According to Nichols et al. (2009), this reading to learn stage is not necessarily for adding new information; instead it is where readers begin to integrate control of their reading. Educators should view this as the point in time where comprehension becomes the main focus. 
In Stage 3, readers begin to "read to learn" (Nichols et al, 2009 p. 3) with the purpose of gaining new information. Fourth through eighth grade students in this stage should engage in much content area reading. Teachers in this stage should explicitly teach comprehension strategies such as making connections, making predictions, visualizing, self-monitoring, and asking questions when meaning is unclear.

In Stage 4, also called the Multiple Viewpoints, students in high school analyze more than one viewpoint, and topics are developed in greater depth. Students encounter a variety of complex materials in various genres that require inferential and critical reading skills. Students benefit from practice in both efficient reading and in study skills (Carnine, Silbert, \& Kame'enui, \& Tarver, 2010).

Stage 5, also known as Construction and Reconstruction, requires students in college and beyond to read for personal, professional, or civic needs. In this stage students are required to integrate their individual knowledge with that of the writers to create original knowledge. In other words, readers construct knowledge and understanding from reading. Readers "analyze, synthesize and make judgments about what they read" (Carnine et al., 2010 p. 2). Students in Stage 4 and Stage 5 apply higher level thinking skills such as analyzing, evaluating, synthesizing, and creating.

With knowledge of Chall's developmental reading stages, educators can evaluate students' reading stage in order to determine a course of action to improve fluency and comprehension. Educators should focus on Stages 2 and 3 for the development of fluency and comprehension. Students who have not mastered these two stages will obviously struggle with the requirements of Stages 4 and 5 . They will need remediation in the earlier stages in order to reach final stages. 


\section{Fluency's Correlation to Comprehension}

To reiterate an important point, fluency's importance cannot be overstated because of its correlation to comprehension. Many reading scholars have confirmed this connection. For instance, Nichols et al. (2009) believed that fluency is the vital element that allows comprehension, which they describe as the ultimate goal of reading. Wexler et al. (2010) also confirmed a "positive and significant relation exists between measures of fluency and comprehension for secondary-level students" (p. 2). The correlation between reading fluency and comprehension proposes that poor reading fluency leads to less comprehension (Hawkins et al., 2011.) Hiebert, Samuels, and Rasinski (2012) claimed the high correlation between CWPM in oral reading and comprehension has greatly influenced the policies and practices that have been implemented in reading education.

Taking a closer look at this correlation, Rasinski (2012) described fluency as the "gateway skill or bridge that leads to comprehension" (p. 517). For instance, fluency can be described as a bridge from word recognition accuracy to text comprehension, and prosody is the link that completes the bridge by connecting it to comprehension. This figure depicts the bridge from word recognition accuracy to text comprehension. It also shows that prosody is the link that connects fluency to comprehension (see Figure 2.1).

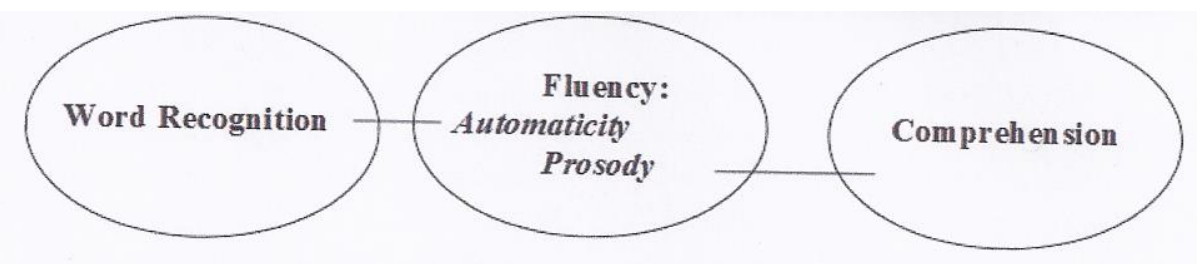

Figure 2.1 - Fluency: A Critical Bridge in Comprehension. (Rasinski, 2012 p. 517) 
Readers need proper fluency to augment textual comprehension. For example, students who exhibit slow, staccato, laborious reading hinder proper comprehension, while improper prosody may cause confusion because words are grouped together in meaningless ways (Paige et al, 2012). Fluent readers read in a manner that builds comprehension or meaning, whereas less fluent readers tend to struggle to construct meaning. In other words, students who experience trouble reading for meaning may be stuck in the word recognition stage. In order to be fluent, a reader must be able to decode and comprehend at the same time (Samuels, 2006). Consequently, readers must become comfortable with recognizing printed words effortlessly, so they can focus on meaning of the words rather than decoding of the words. Readers reach automaticity of word recognition through repeated practice over time. Kuhn et al. (2010) added insight into automaticity as they suggested processes are deemed automatic when they "possess four properties: speed, effortlessness, autonomy, and lack of conscious awareness" (p. 231). They also proposed extensive reading of connected text in which every engagement with a task lays down a trace in memory. Readers must repeatedly read to build a knowledge base that can be retrieved instantly from memory rather than slower algorithmic processing (Kuhn et al.). Hence, repetition or RR allows consistent practice that builds automaticity.

In order to develop automaticity and fluency, students should be given many opportunities to read at an independent or instructional level (Nichols et al., 2009). For maximum effect, a teacher should guide and model this instruction. Since repeated practice frees the reader from focusing on decoding, they are able to examine the text for meaning. As in most athletic-based skills where perfect practice makes perfect, reading 
also takes perfect practice. Teachers enhance perfect practice when they model and scaffold fluent reading (Nichols et al., 2009).

Klauda and Guthrie (2008) support the link between fluency and comprehension as they describe the automaticity theory hypothesized by LaBerge \& Samuels. They believe that the verbal efficiency theory enhances reading comprehension (Klauda \& Guthrie, 2008). As a student recognizes words faster, word recognition ultimately becomes automatic. Students can now use attention that was once required for the job of word decoding to be dedicated to comprehension.

Rather than considering the relationship between comprehension and fluency as a link, Hudson et al. (2009) suggested that evidence can support the relationship between reading fluency and comprehension can be regarded as reciprocal. For instance, reading rate and accuracy facilitate reading comprehension, while comprehension facilitates quick and accurate reading of the text. They felt the smarter view may be to see comprehension predicting fluency rather than fluency predicting comprehension (Hudson et al. 2009). Furthermore, Hudson et al. (2009) claimed fluent, effortless reading is a result of many sub-processes that interact with one another. These elements, that all go into fluency, include sight word automaticity, decoding fluency, orthographic knowledge, and integration of multiple cues. They promoted a multileveled framework for reading comprehension that begins with phonemic awareness and progresses through each level to reach comprehension (see Figure 2.2). 


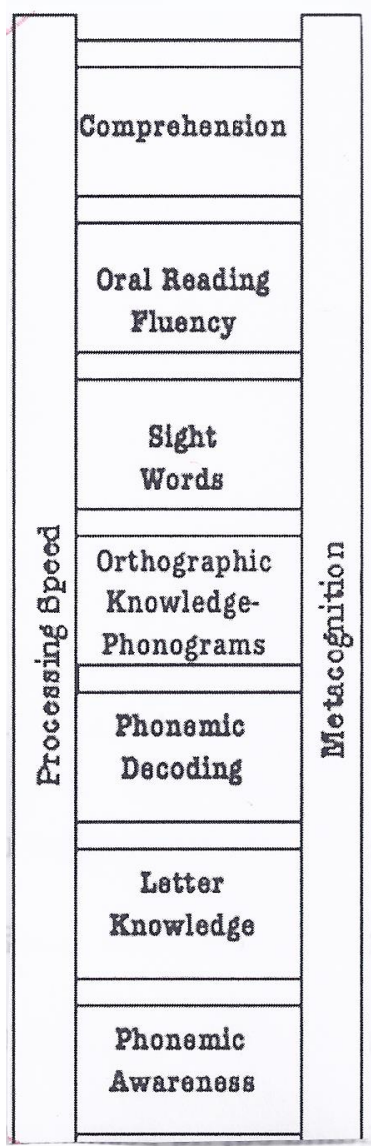

Figure 2.2 Comprehension Ladder. (Hudson et al., 2009, p. 19)

According to Hudson et al. (2009), after students developed the basic skills of phonemic awareness, letter knowledge, orthographic knowledge phonograms, the next element of reading fluency included sight word automaticity, which means sight of the word "activates spelling, pronunciation, and meaning immediately in memory" (p. 15). Additionally, students stymie fluency if too many words have to be identified analytically (Hudson et al., 2009). Students who spent three to four more times than peers decoding a small passage, tended to quit reading because it became too exhausting (Hudson et al, 2009). Thus, automaticity in the lower level processes such as fluency, promotes quicker reading and comprehension. 
Educators who understand the complex nature of comprehension realize the value of automaticity in the lower level reading skills because comprehension takes so much cognitive energy. The National Reading Panel Report gave a simple definition of comprehension when they claimed it is "the act of understanding and interpreting the information within a text" (Shanahan, 2006, p. 18). This report also described comprehension as more than just passive remembering, but also constructing meaning. Furthermore, readers interpret the information through their own schemas while using the organizational plan of the author to make connections about the ideas. Therefore, reading scholars portrayed comprehension as active and changing. McCallum et al. (2011) proposed that comprehension requires actively applying strategies designed to monitor and enhance comprehension. According to McCallum et al. (2011), some of these strategies included making connections based on background knowledge, making predictions about the text, visualizing the content of the text, asking clarifying questions when confused, using summarizing strategies, and self-monitoring when comprehension breaks down. Therefore, as educators understand comprehension's complex processes, they understand the importance of fluency and automaticity in the lower level reading processes.

A brief review of the literature review thus far, reveals that educators and researchers have placed special emphasis on fluency instruction since the National Reading Panel Report deemed it as one of the five pillars of effective reading instruction. In the complex process of reading, a high school student requires intense explicit reading instruction, especially in today's educational world when CCSS standards stress high levels of reading expertise. One vital component of effective reading instruction includes 
fluency because of its inherent link to comprehension. As a reader's fluency increases, they seem to experience an apparent increase in comprehension. Some secondary students, however, lack fluency which can lead to struggling comprehension and academic problems. Nevertheless, readers seldom participate in fluency instruction after the third grade, and some junior high and secondary students still need to develop this skill.

\section{Methods to Increase Fluency}

What can be done to increase secondary student's fluency? One answer lies in Gorsuch and Taguchi's (2010) assertion that teachers and administrators do not clearly understand the role of rapid, automatic word recognition. They also stated that teachers may be "unaware and unconvinced of the role that increased reading fluency plays in reading comprehension and, as a result, may not see the utility of devoting class or personal time to repeated reading or, indeed any reading fluency activity" (Gorsuch and Taguchi, 2010, p. 29). Thus, experts in fluency can inform teachers and administrators about the benefits of reading fluency and instructional methods.

Other reading experts suggested a variety of different activities to develop fluency. For instance, Nichols et al. (2009) advocated that a wide variety of fluency building activities promotes continued engagement. These activities included methods such as Fluency-Oriented Reading Instruction or FORI, Radio Reading, Phrased Reading and Fast Start (Nichols et al., 2009). Other researchers also advocated extensive reading. Gorsuch and Taguchi (2010) define extensive reading as one in which learners choose materials from a collection of graded readers that allows them to read for pleasure in both the classroom and outside of the class room. These readers are encouraged to engage in 
sustained silent reading and to read for meaning. Nichols et al. (2009) believed fluency is developed through wide and deep reading practice. Paige et al. (2012) defined wide reading as practice in reading that involves a variety of topics, texts, and genres with an engaging response activity. Additionally, they defined deep reading, which includes RR, as a more in-depth reading in which readers who struggle with fluency, read the same text over many times before going on to a new text (Paige et al., 2012). Students, especially those struggling readers, may need to practice a passage several times before moving on to the next because their first reading is not fluent. Students constantly engaged in disfluent reading do not improve without more in-depth practice, such as RR provides. Kostewicz (2012) created a case that just like athletic skills or music skills, which take great amounts of practice and repetition to master, so too fluent reading takes many hours of practice. Kostewicz (2012) promoted RR, which is a form of systematic, deliberate practice that focuses on ORF. He liked RR because of its efficiency, effectiveness, and adaptability to a wide range of classroom reading levels (Kostewicz, 2012). As stated earlier, in the RR procedure students repeatedly reads a passage until they meet the prerequisite CWPM or until they reach a maximum of four to five repeated readings. Therrien et al. (2012) concurred with Kostewicz in supporting RR as a comprehensively researched fluency intervention that has proven successful for students with disabilities as well as those without. Nichols et al. (2009) proposed that "repeated reading is the most recognized approach for developing fluency" (p. 5), while Begney et al. (2009) revealed that current meta-analyses have demonstrated successful results using RR procedures. On the other hand, O'Keeffe, Slocum, Burlingame, Snyder, and Bundock (2012) claimed less optimism for the effectiveness of RR. O'Keeffe and 
colleagues conducted research on thoroughly researched empirically supported treatments (EST) that have been shown to increase student outcomes (O'Keeffe et al., 2012). Their research felt that the previously used review systems to evaluate RR research "resulted in the conclusion that that RR did not have enough high quality research support to be considered an EST"' (O'Keeffe et al., 2012, p. 333). They claimed that previous research on RR used studies with a wider range of quality, whereas they used very strict criteria to judge the quality of each study.

\section{Origin of Repeated Reading}

Therrien (2012) postulated RR's effectiveness may be attributed to the many opportunities students encounter to master words, sentence, and paragraphs in a passage. Interestingly, Samuels, an early expert in the field of automaticity and fluency, created RR because he also believed that students need repeated practice to reach automaticity. Samuels believed that students become automatic readers through practice over an extended period of several years. He asked, "Who are the most highly trained people? How do they get their training" (Samuels, 2006, p. 337)? He answered that musicians and athletes are very highly trained individuals. He declared their training similar to the training readers needed. For example, Samuels (2006) declared that in both types of training a student was instructed to follow a set procedure. First, the athlete or musician started with just one part at a time. Next, the athlete or musician practiced that part, first to accuracy and then to automaticity. After the parts were learned, the athlete or musician practiced the entire movement until the full automaticity phase is achieved.

Using this information, Samuels (2006) realized that reading was not taught this way because teachers had to cover material so quickly. This pace was fine for average or 
above students; however, for struggling readers the pace was too fast. Every day added more frustration to their inability to read and keep pace. Hence, he tried his new instructional method called RR, which he based on the training of athletes and musicians (Samuels, 2006). In the RR procedure, he broke the longer passage into smaller 150 word chunks. He explained to the students the importance of practice in becoming better at sports and at reading. Next, he modeled reading the passage. Each student practiced by themselves, and when they could reach their goal of 85 words per minute, they read it to a teacher who recorded their score. Then they started the process all over with the next passage.

Samuels discovered some interesting results. For example, since word overlap occurred from one passage to the next, students took fewer repeated readings to reach their goal. As they practiced reading each passage several times, their oral reading expression improved. Finally, they began to sound like good readers. Samuels (2006) stated that from his initial description of the study, "there have been several hundred research articles published by other scholars who used the method" (p. 338). He never intended RR to be a reading curriculum, just a component to add to reading instruction. Gorsuch and Taguchi (2010) flaunted the value of RR when they stated, "RR seems to enable readers to read in larger and more syntactically and phonologically appropriated phrases, considered to be a hallmark of reading fluency" (p. 32). In one study they conducted, the RR experimental group read significantly faster and comprehended new passages significantly better than the control group (Gorsuch \& Taguchi, 2010). Moreover, they felt the quantitative data collected on RR may not reveal the full benefits or unexpected effects that some qualitative data might reveal. For 
instance, they found that some participants in their RR experiment were not only more motivated to read, but they also reported using a variety of top-down and bottom-up reading strategies along with metacognition strategies (Gorsuch and Taguchi, 2010, p. 54). Finally, they proposed that their research using RR suggested a long-term, cumulative effect as participants increased their fluency rate from an average of $163 \mathrm{wpm}$ to an average of $218 \mathrm{wpm}$ on passages that were read for the first time (Gorsuch and Taguchi, 2010).

Those opposed to RR state that it is too one dimensional causing students to focus only on reading fast. This is dangerous because students may not attend to the meaning and may not use proper phrasing and expression. Samuels (2006) also cautioned that some students can read orally with speed, but have trouble with comprehension.

Although not opposed to RR, Kuhn et al. (2010) did challenge the emphasis placed solely on accuracy and automaticity at the expense of other important parts of fluent reading.

\section{Measuring Fluency and Comprehension}

Paige et al. (2012) stated the ability to measure both a student's level of achievement in fluency and monitor their progress is the key to successful fluency teaching. Previously mentioned, reading rate supplies educators with a way of measuring students' level of automaticity in word recognition. According to Hudson et al. (2009), the most common method of assessing reading fluency, called Curriculum-Based Measurement/ Oral Reading Fluency, (CBM/ORF) measured the number of words read correctly in one minute (CWPM). Additionally, Hudson et al. (2009) suggested this method of assessing oral reading fluency has "rich evidence of its validity and reliability" (p. 20). Hudson et al. (2009) also mentioned, however, that this method for assessing 
fluency may be not be completely accurate because short one minute assessments may not accurately reflect students' ability to sustain this rate over a longer time in a longer passage. Measuring ORF consists of specific steps. Rasinski (2010) described the specific steps in measuring ORF (see Appendix A).

Very little, if any, fluency norms for secondary students can be found.

Consequently, one method for determining a minimum level of ORF for secondary students uses Hasbrouck and Tindal's (2006) spring fluency norms for eighth grade. Using this table, a high school student should read at least 151 correct words per minute in order to achieve a minimum eighth grade spring $50^{\text {th }}$ percentile score (see Table 2.1). Table 2.1

Eighth Grade ORF Target Fluency Norms

\begin{tabular}{llll}
\hline Percentile & Fall CWPM & Winter CWP & Spring CWPM \\
\hline 90 & 185 & 199 & 199 \\
75 & 161 & 173 & 177 \\
50 & 133 & 146 & 151 \\
25 & 106 & 115 & 124 \\
10 & 77 & 84 & 97 \\
\hline
\end{tabular}

Note. (Hasbrouck \& Tindal, 2006).

Educators cannot directly observe the complex processes involved in comprehension like they can in fluency or vocabulary. Thus, assessment of all the underlying skills involved in comprehension proved difficult (Bellinger \& DiPerna, 2011). According to Bellinger and DiPerna (2011) some of the assessments used to measure comprehension include fill in the blank or cloze formats, multiple choice questions, short answer, true or false questions, and story retell. Researchers found no perfect way to measure comprehension as each of these ways possesses its own inherent limit in validity and usability. 
Bellinger and DiPerna's (2011) suggested method for measuring comprehension relies on the story retell or RTF. This method coincides with DIBELS ORF task. They also used this measure with ORF to prevent using ORF as a measure of speed without focusing on content (Bellinger and DiPerna, 2011). These researchers found the RTF method time efficient because it did not require question writing (Bellinger \& DiPerna, 2011). Teachers can score the results of the retell in multiple ways. For example, they can be scored using to total number of words retold, or a percentage of idea units retold, or a percentage of content words retold. Samuels (2006) also addressed ways to keep RR from becoming only a speed-reading task. He stated, "My search for ways to measure fluency continues. I have long advocated that to determine if a student is fluent, the student should be given a task requiring him or her to decode and comprehend at the same time" (Samuels, 2006, p. 343). To avoid students purely reading for speed, he advocated that the student read and then tell everything that he could remember about the passage. As previously stated, Rasinski (2012) disliked the idea of fluency instruction that only focuses on speed because he believed fluency was also reading for meaning. He felt so strongly about reading for speed without meaning that he called it "wrong" (Rasinski, 2012, p. 517). Using the expertise of Samuels (2006) and of Bellinger and DiPerna (2011), this research will measure the fluency component by using the number of words retold in one minute that relate to the passage and its content. The RTF will not include repeated ideas or words or information that is not related to the story.

This method of measuring comprehension does have some limitations. Since a child is only allowed to read for one minute, the amount of meaningful information that can be gleaned is limited. Thus, it may not be a sufficient measure of comprehension. 
Bellinger and DiPerna (2011) also proposed the RTF may not be good indicator of reading comprehension because of the difficulty of gathering an accurate record of a student's retell. In their own study they found that fluency-based story retell task was "not a strong indicator of reading comprehension skills among fourth grade students" (Bellinger \& DiPerna, 2011, p. 425).

On the other hand, however, their evidence did concur with other research that ORF scores alone may be useful indicators of reading comprehension (Bellinger \& DiPerna, 2011). Some might even conclude that the retell component is not necessary to assess comprehension since research has shown positive correlations between DIBELS one minute fluency reading levels and comprehension. For example, Bellinger and DiPerna (2011) stated the results give evidence that the Dynamic Indicators of Basic Early Literacy Skills" (DIBELS) one-minute Oral Reading Fluency measure is a "strong predictor of children's reading comprehension (p. 417). Roehrig, Petscher, Nettles, Hudson, and Torgesen (2008) examined the relationship between DIBELS Oral Reading Fluency (DORF) measure and a couple of measures for reading comprehension that include the Florida Comprehensive Assessment Test (FCAT) and the Stanford Achievement Test (SAT). Roehrig et al. (2008) confirmed this as the results of their study to examine the relationship between DIBELS ORF and reading comprehension on the FCAT-SSS and the SAT-10 show "the correlations of ORF with both FCAT-SSS and SAT-10 were high $\left(\mathrm{r}_{\mathrm{s}}-.70-.71\right)$ and consistent with previous findings about the relationships between oral reading fluency and reading comprehension" (p. 360). Thus, the evidence appears to indicate that ORF may be a better indicator of comprehension than RTF because of the evidence of ORF's high correlation to comprehension. 
With limited research on fluency at the high school level and the wavering effectiveness of the story retell in gauging comprehension, more research on fluency and reading instruction at the secondary level needs to be conducted. Wexler et al. (2010) indicated a great deficiency in the knowledge of useful practices to increase struggling secondary school fluent reading ability. Rasinski et al. (2009) echoed this lack of research as they "suggest that more research is called for into the role of reading fluency among adolescent students, especially those students experiencing difficulty in achieving high levels of literacy” (p. 351). Finally, Wexler et al. (2010) advocated more research on the efficacy of RR on high school students. Therefore, researchers in the field of reading emphatically stated that more research on fluency and reading instruction at the secondary level needs to be conducted.

\section{Conclusion}

Researchers' and educators' recent interest in fluency (Hudson et al., 2009; Klauda \& Guthrie, 2008; Kuhn et al., 2010) is significant because of the complexity of reading skills the Common Core State Standards mandated (Hiebert \& Pearson, 2012). The research in the literary review suggested that high school students need fluency instruction in the curriculum because evidence showed that a significant number were deficient in this area (Begney et al., 2009; Marchand-Martella et al., 2010; Murray et al., 2012; Paige et al., 2012; Wexler et al., 2010) and they were not receiving instruction needed to improve (Paige et al., 2012; Wexler et al., 2010). Furthermore, the review enumerated the many dangers for secondary students who cannot read fluently (Hawkins et al., 2011; Hudson et al., (2009); McComas et al. 2009; Rasinski, 2012; Wexler et al., 2010). These dangers were deemed crucial because today's high school students are 
expected to read at increasingly complex levels called for by College and Career Ready Standards. Even though these standards call for complex reading skills, the development of such complex skills still require mastery of basic reading skills such as fluency (Hiebert and Pearson, 2012). Since researchers find difficulty agreeing on one definition of fluency (Bellinger \& Diperna, 2011), multiple definitions were examined. The prevailing view, however, emphasized the ability to read a text aloud with accuracy, speed, and prosody that produced comprehension (Kuhn et al. 2010). Researchers believed that fluency plays a critical role as the bridge or gateway that allows student to make meaning (Gorsuch \& Taguchi, 2010; Rasinski, 2012). The research also demonstrated that scholars have some differing views on the exact ways that fluency develops (Rasinski, 2012; Samuels, 2006; Hudson et al., 2009; Nichol et al., 2012). Some asserted a bottom-up view, while others chose a top-down view. In the predominant view, however, readers must attain automaticity at the word recognition level in order to free cognitive resources for comprehension (Rasinski, 2012; Samuels, 2006). Readers attain this automaticity over time through repeated practice in which proper reading is teacher-directed and modeled (Kostewicz, 2012; Paige et al., 2012; Rasinski, 2012). Although prosody was not explored in depth, the literature review acknowledged that it also plays a vital role in comprehension (Kuhn et al. 2009). Reading scholars considered RR to be a well-known, proven instructional technique to improve reading fluency (Kostewicz, 2012; Samuels, 2006; Shanahan, 2006; Therrien et al., 2012). Some researchers agreed that fluency instruction and assessment should include a comprehension component, or fluency instruction and assessment just became a speed reading task (Bellinger \& DiPerna, 2011; Rasinski, 2012; Samuels, 2006). ORF 
measured the speed and accuracy components of fluency in CWPM, while story-based RTF described one time efficient way of measuring comprehension by the number of words recalled from the story in one minute (Kuhn et al. 2010). More researchers confirmed, rather than dissented, that RR appears to significantly increase fluency in primary grades and also at the secondary level, although limited research has been conducted at this level (Paige et al., 2012; Rasinski et al., 2009; Rasinski, 2102; Wexler et al., 2010). Finally, the literature review also revealed the need for more research on fluency and reading development at middle school and secondary levels (Hawkins et al., 2011; Rasinski et al., 2009; Wexler et al. 2010). 


\section{Chapter 3: Methodology}

The literature review has stressed the need for more research in the area of secondary students' fluency. This experiment, which was modeled after a number of similar studies, (Begney et al., 2009; Lo et al., 2011; Paige et al. 2012, Wexler et al., 2012) intended to add to the available research on the topic of the efficacy of RR on secondary students ORF and RTF. This quantitative research was a controlled experiment with a pretest-posttest control-group design that intended to answer the question the following questions:

Research questions:

(a) Does repeated one minute reading of instructional level reading passages improve oral reading fluency as measured by increase in the number of words read per minute?

(b) Does repeated one minute reading of instructional level reading passages with a retell activity improve retell fluency as measured by the number of words retold from reading passage?

Null hypothesis one states that RR does not produce a difference in ORF scores between a group of students that practice RR and those that do not practice RR. The alternative hypothesis states the group that uses RR will score higher on the ORF than the group that does not. Furthermore, null hypothesis two states that that RR does not produce a difference in RTF scores between an experimental group that practice RR and a control group that does not practice RR. The alternative hypothesis states the group that uses RR will have a RTF score higher than the group that does not. 


\section{Rationale}

One of the primary aims of this study was to add to the limited amount of research on how RR impacts secondary students' reading fluency and comprehension. Based on the study by researchers (Lo et al., 2011; Gorsuch and Taguchi, 2010; Wexler et al., 2010) in the Literature Review, I chose RR as the method in this intervention. Paige et al. (2012) declared that fluency is automatic word recognition which is most often measured by reading speed. Therefore, in these repeated one-minute-readings ORF was measured by CWPM total. In order for RR to measure comprehension, I added a storybased RTF component that the Bellinger and DiPerna (2011) study suggested. This also complies with Rasinski's (2012) and Samuel's (2006) suggestion that educators add a comprehension component to ORF. I measured the comprehension component using the number of words retold per minute that accurately represented ideas in the passage. I also wanted to determine if RR would be helpful instructional method in the secondary curriculum. Finally, I wanted to evaluate the general fluency rate of secondary students.

The purpose of the experiment was to determine whether changing the RR interventions (the independent variable) significantly affected the participants' scores on ORF and RTF (the dependent variable). The control group did not complete repeated reading, whereas the $\mathrm{RR}$ experimental group did complete at least $12 \mathrm{RR}$ interventions. The first dependent variable was the difference in the ORF score in a pretest and posttest design. The second dependent variable two included the difference in the RTF score of each group in a pretest-posttest design. 


\section{Participants and Setting}

I conducted this study at a county high school in southern Ohio. The high school serves approximately 559 students--281males and 278 females. In the high school, $93.4 \%$ of the students were classified as Caucasian, $1.9 \%$ were classified as Black, $2 \%$ were classified as two or more races, and the remaining $2.7 \%$ were classified as other races (National Center for Educational Statistics, 2010). Approximately $45 \%$ of the students participated in free and reduced lunch.

The sample for this experiment consisted of approximately 32 randomly selected secondary students who attended this high school. This study used a proportional number of male and female students from each grade. Proportional stratified sampling was utilized in order to choose a proportional number from each of the 4 grades, which includes freshman through senior students. Students were chosen using proportionally equal numbers from each grade and each sex so that the maturation level of the students and the sex of the students was not a confounding variable. Each student was given a number from one to the number of students in that specific grade and gender. The Research Randomizer then generated random numbers that corresponded to the required number of participants in each grade and gender (Urbaniak \& Plou, 2008). Next, the participants were randomly split into sixteen participants in the RR experimental group and sixteen in the control group. An independent samples $t$ test proved there was not a significant difference in the GPA of the two groups. The results were nonsignificant, $t$ $(30)=-0.39, p<.05$. Thus, the GPA of the RR group and the control group appears not to affect the outcome. The number of males and females selected was also equal (see 
THE EFFICACY OF REPEATED READING

Table 3.1). IQ scores, however, which were not available, were not able to be factored into the equality of the groups.

Table 3.1

Grade Level and Gender Breakdown of Participants

\begin{tabular}{llc}
\hline Grade & Males & Females \\
\hline Ninth & 5 & 4 \\
Tenth & 5 & 5 \\
Eleventh & 3 & 4 \\
Twelfth & 3 & 3 \\
\hline
\end{tabular}

\section{Material}

The material used for the treatments or the interventions came from the AIMSweb CBM eighth grade reading probes. As Gorsuch and Taguchi confirmed fluency development needs to be at "a reading level that is not too difficult in order to maximize the fluency-building effects of the treatment." (p. 35). More specifically, Lo et al. (2011) proposed fluency development needs to be at students' instructional level or independent level. All participants were enrolled in the freshman through senior class. Therefore, an eighth grade passage should be considered the instructional or independent level of most of these students. The pretest and posttest material came from the three eighth grade benchmark assessments of AIMSweb. The twelve intervention passages came from a combination of AIMSweb practice probes and non-fiction content area topics. The online OKAPI probe generator created the non-fiction content area topics. These passages were rated at or below the eighth grade reading level as determined by an analysis using the Dale-Chall readability index and the Spache readability formula (see Appendix B for a sample a probe). All non-fiction passages were rated at or below the eighth grade level for readability. The rationale for the content area passage was to 
THE EFFICACY OF REPEATED READING

evaluate student fluency on both fiction and non-fiction passages such as those read in content areas.

\section{Procedure}

Once the participants were selected, both parents and students were required to sign a consent form in order to participate in the study. Students could opt out of the study at any time. Students were rewarded with a t-shirt for completion of the project. Every student who started the experiment completed it. The RR experimental group of 16 students and the control group of 16 students were given a pretest of three different CBM probes in which they read each passage for one minute and then retold each passage in one minute. Errors were scored according to Marchand-Martella's (2010) definition found in the definition section of this paper. Self-corrections were not counted as mistakes. Both ORF and RTF score for each passage were recorded. The mean of the three scores in both the ORF and RTF counted as the score for the initial assessment. The control group, which consisted of 16 students, received no interventions, while the RR experimental group received at least 12 treatments lasting approximately 20 to 30 minutes. In the 12 treatments, each student was matched with a peer. Most interventions were administered during students' study hall period in a separate classroom. This group's daily intervention consisted of three repeated readings of 1 minute each and two timed retells of 1 minute per intervention. These daily RR interventions were on the same passage. The students read one new passage each day. The RR experimental group had one day of training in how to score the ORF, which included understanding errors, omissions, substitutions and self-corrections. Self-corrections did not count as an error. Students were trained in the RTF scoring procedures, which included disregarding 
repetitions or ideas not found in the passage. The students recorded their partners' (ORF), which was determined by the number of words read correctly in one minute (CWPM) and their story-based RTF which was determined by the number of correct words in the passage retold per minute (see Appendix C for a sample score sheet). Students also graphed their median score in ORF and highest score for RTF for each day. If students missed more than the required 12 sessions, they met with me for make-up sessions. After the twelve interventions, I post-tested both groups of students on the same initial reading passages. Again, the mean score for the three reading passages in both the ORF and RTF were calculated. To ensure the reliability of the initial and final tests, students were prompted with the same instructions prior to each test: "Please read in a manner that allows you to read as quickly as possible and at the same time allows you to remember as much as possible." In order to maintain the ethical integrity of my study, I strove to safeguard the confidentiality of the group members and their scores. Students were allowed them to withdraw at anytime to minimize the pressure to participate in the study.

The validity of the experiment came from following the procedures outlined in the literature review which stated that reading rate provide a way of determining a reader's automaticity level. The research found that $\mathrm{CBM} / \mathrm{ORF}$ assessment provides a quick and valid measurement of fluency. The steps outlined in Appendix A were followed to determine ORF and RTF. The validity of the study was also ensured by evaluating the extent to which students were correctly scoring progress monitoring of ORF and RTF intervention sessions. Data was collected on 11 percent of the total student ORF monitoring and RTF monitoring calculations. The percentage difference between my 
total CWPM number and the students' was calculated. Inter-rater reliabilities showed the students were accurately scoring ORF with an inter-rater reliability of $99.8 \%$. The RTF progress monitoring scores, however, confirmed the literature review findings that an accurate retell count is not as reliable. For instance student inter-rater reliability for RTF in my experiment was $84.9 \%$.

Pretest and posttest procedures included AIMsweb CBM benchmark monitoring assessments for students reading at or below eighth grade instructional level. The same probes for the pretest and posttests were used. I also followed a list of procedures for each pretest and posttest (see Appendix D). Due to a technical error, the inter-rater reliability of testing procedures could not be validated.

The mean of each student's three ORF and RTF scores was calculated. I calculated the difference between the students' initial score on the pretest and their final score on the posttest, along with the mean difference and standard deviation for each group. Finally, an independent samples $t$-test determined the validity of the hypothesis. The null hypothesis was rejected in both the ORF and RTF, and the data confirmed alternate hypotheses in both ORF and RTF. 


\section{Description of the Data}

\section{Chapter 4: ANALYSIS}

The results of the data seem to indicate that RR intervention significantly increases secondary students ORF and RTF scores. These results concur with similar studies in the literature review (Lo et al., 2011; Wexler et al., 2009). An independent samples $t$-test on ORF and RTF between the control group and RR group was performed. The first null hypothesis stated that RR did not affect the ORF score of students. The null hypothesis was rejected because the results were significant. For example, $t(30)=4.12$, $\mathrm{p}<.001$. The effect size, as measured by $\mathrm{r}_{\mathrm{pb}}^{2}$, was .40 . The alternate hypothesis, which states that repeated reading intervention does significantly increase ORF, was accepted.

The second null hypotheses two stated that RR did not affect the RTF of students. I again rejected the null hypotheses because the results were significant. For example, $t(30)=4.58, \mathrm{p}<.001$. The effect size, as measured by $\mathrm{r}_{\mathrm{pb}}^{2}$, was .44 . The alternate hypothesis, which states that RR does significantly increase RTF scores, was accepted. Table 4.1 contains a summary of the statistical results (see Table 4.1). 
THE EFFICACY OF REPEATED READING

Table 4.1

Group Differences for Fluency Tasks between Groups Did or Did Not Participate in Repeated Reading

\begin{tabular}{lccccccc}
\hline & \multicolumn{2}{c}{ RR Group $^{\mathrm{a}}$} & & \multicolumn{2}{c}{ No RR Group $^{\mathrm{b}}$} & & \\
\cline { 2 - 3 } Fluency measure & $M$ & $S D$ & & $M$ & $S D$ & $t(30)$ & $d^{*}$ \\
\hline ORF & 22.73 & 16.24 & & 3.17 & 9.88 & $4.12^{* * * *}$ & 1.45 \\
RTF & 29.20 & 16.99 & & 5.25 & 12.20 & $4.58^{* * * *}$ & 1.62
\end{tabular}

Note. ${ }^{a} n=16,{ }^{b} n=16$. The statistics were calculated using Microsoft Excel. (see Appendix E for ORF $t$ test calculation and see Appendix F for RTF $t$-test calculations). See Appendix G for Cohen's d calculation (Scopes, 2008).

*Cohen's $d$ $* * * \mathrm{p}<.001$

\section{Data Analysis}

In the RR group which participated in at least 12 interventions in RRs, 15 out of 16 students showed improvement in ORF. The mean gain by this group was 22.73 CWPM, while out 11 out of 16 in the control group showed improvement. The mean gain of the control group was 3.17 CWPM. Figure 4.1 depicts the ORF gains of each group from the initial test to the final test (see Figure 4.1.). Figure 4.2 depicts the RTF gains of each group from the initial test (see Figure 4.2). I created all of my graphs using the "Create a Graph" service from the National Center for Education Statistics (Create a Graph, n.d.). 
THE EFFICACY OF REPEATED READING

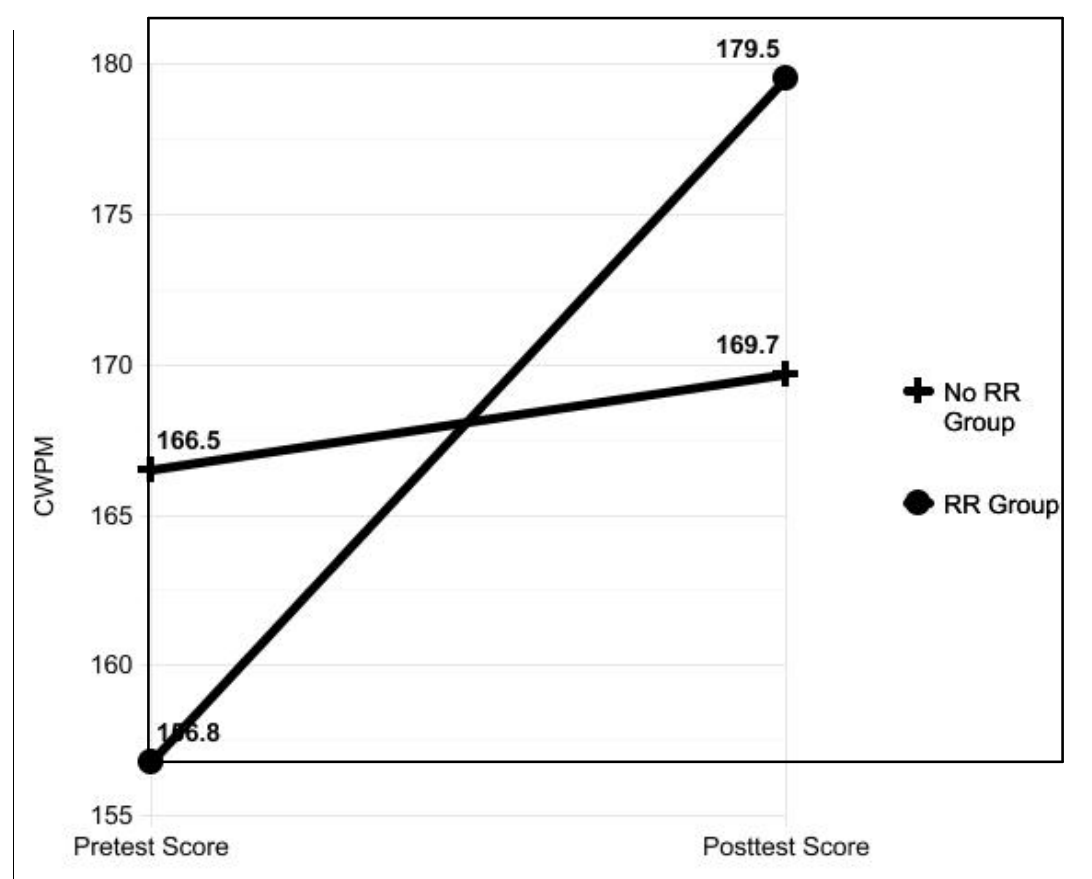

Figure 4.1 Results of Pretest-Posttest Mean ORF Scores of Each Group

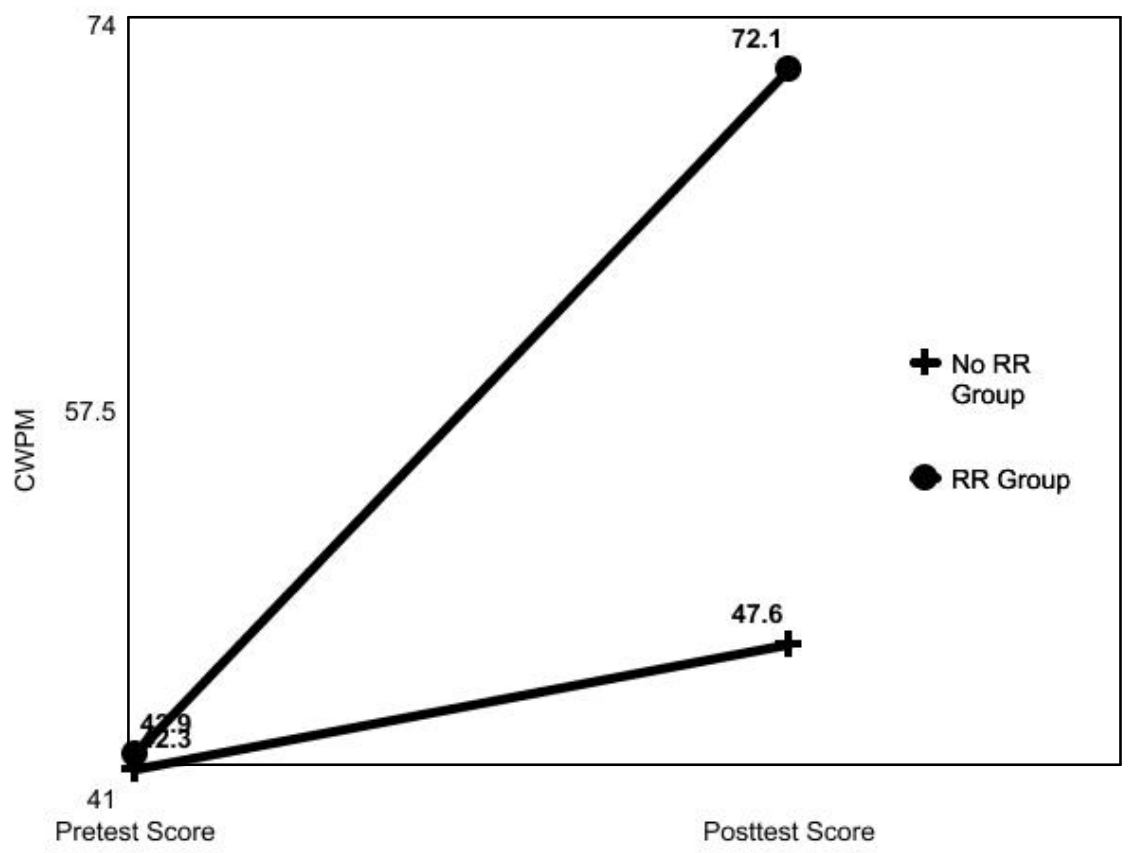

Figure 4.2 Results of Pretest-Posttest Mean RTF Scores of Each Group 


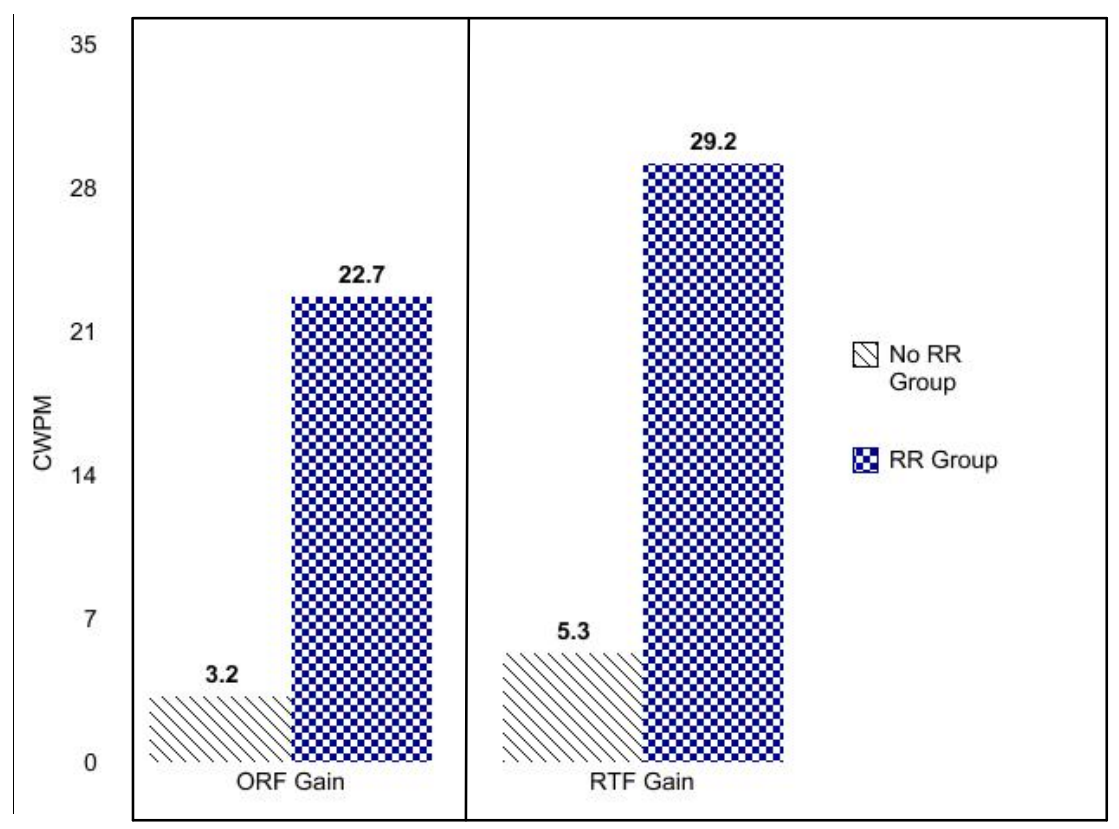

Figure 4.3 Results of the ORF and RTF Mean Gain in Each Group

The ORF standard deviation of the RR group was 16.24; the control group had a standard deviation of 9.88. Only 1 out of 16 in the RR group did not improve in ORF, while 5 out of 16 did not improve in the control group. Thus, the mean ORF score for RR group $(M=22.73, S D=16.24, n=16)$ was significantly greater than the score for the control group $2(M=3.17, S D=9.88, \mathrm{n}=16)$ using the independent samples $t$-test for variance, $t(30)=4.12, \mathrm{p}<=.001$. The ORF effect size, as measured by $\mathrm{r}_{\mathrm{pb}}^{2}$, was .40 , which was moderately significant.

The RTF standard deviation of the RR group was 16.99; the control group had a standard deviation of 12.20 . Only 1 out of 16 in the RR group did not improve in RTF, while 3 out of 16 did not improve in the control group. Thus, the mean RTF score for RR group $(M=29.2, \mathrm{SD}=16.99, n=16)$ was significantly greater than the score for the control group $2(M=5.25, \mathrm{SD}=12.19, n=16$.$) using the independent samples t-test for$ unequal variances, $t(30)=4.58, \mathrm{p}<=0.001$. The RTF effect size, as measured by $\mathrm{r}_{\mathrm{pb}}^{2}$, 
was .44, which was moderately significant. Individual results show that students in the RR group made greater gains in ORF (see Table 4.2).

Table 4.2

Oral Reading Fluency Gains by Individuals in Each Group

\begin{tabular}{lcc}
\hline \multicolumn{1}{c}{ Scale } & RR Group & Control Group \\
\hline 40 or more CWPM & 2 & 0 \\
30-39 CWPM & 2 & 0 \\
20-29 CWPM & 5 & 0 \\
$10-19$ CWPM & 3 & 4 \\
$1-9$ CWPM & 3 & 7 \\
0 or less CWPM & 1 & 5 \\
\hline
\end{tabular}

The highest ORF gain by the RR group was 61 CWPM, compared to 17.9 for the control group. Only one person in the RR group showed no improvement, while 5 people in the control group showed no improvement. Overall, nine out of 16 or $56 \%$ of the RR group's ORF improved by at least 20 CWPM, none of the control group's ORF improved by at least 20 CWPM.

Individual results also seem to indicate that students in the RR group made greater gains in RTF. The highest RTF gain by the RR group was 58.3 CWPM, compared to 23.3 for the control group. Only one person in the RR group showed no improvement from 10 and below while 10 people in the control group showed no improvement in 10 and below category. Overall, 10 out of 16 or $62.5 \%$ of the RR group's RTF improved by at least 20 CWPM, while one out of 16 or $6.25 \%$ of the control group's RTF improved by at least 20 CWPM (see Table 4.3). 
THE EFFICACY OF REPEATED READING

Table 4.3

Retell fluency Gains by Individuals in Each Group

\begin{tabular}{lcc}
\hline \multicolumn{1}{c}{ Scale } & RR Group & Control Group \\
\hline 40 or more CWPM & 5 & 0 \\
$30-39$ CWPM & 2 & 0 \\
$20-29$ CWPM & 5 & 1 \\
$10-19$ CWPM & 3 & 5 \\
$1-9$ CWPM & 0 & 7 \\
0 or less CWPM & 1 & 3 \\
\hline
\end{tabular}

Students in the RR group who made the greatest gains on the pretest and posttests, also showed the greatest gains in the intervention sessions. The following graphs found in Figures 4.4 - 4.35 depict the median score out of three rereading passages in ORF for each student in the intervention sessions. They also depict the higher of two retells in each intervention session. The other graph shows the individual results of the identical pretest and posttest. For these scores the mean of three different passages was calculated in both the ORF and RTF (see Figures 4.4 - 4.35).

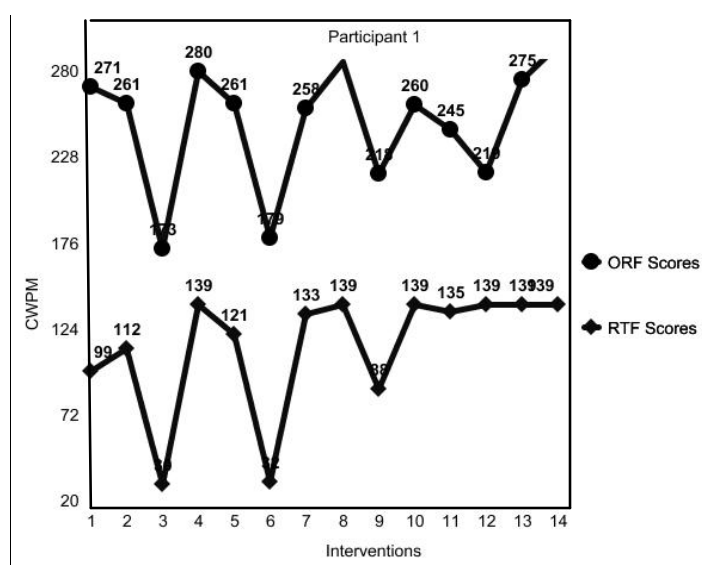

Figure 4.4 Intervention Results

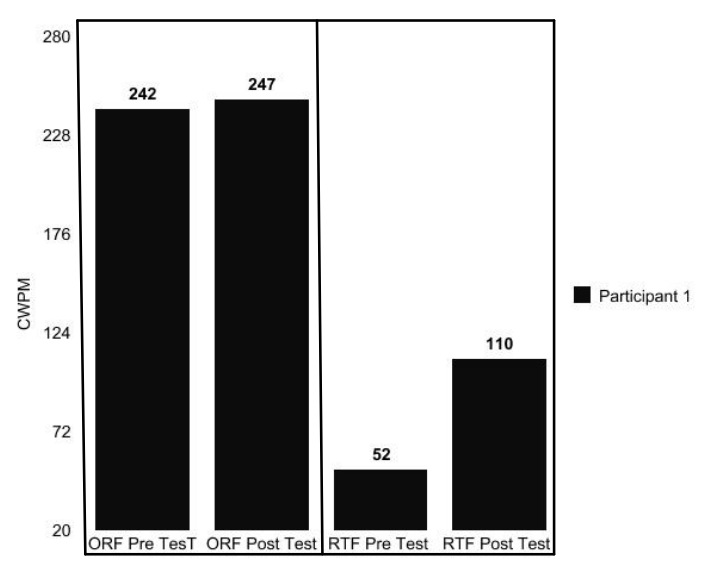

Figure 4.5 Pretest and Posttest Results 


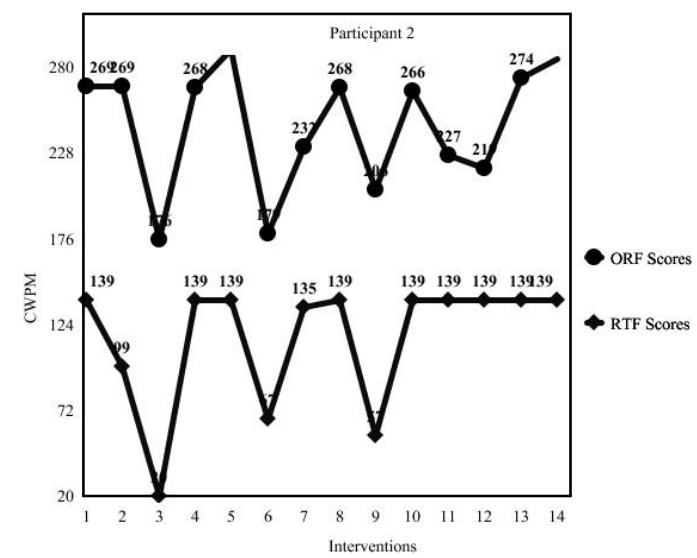

Figure 4.6 Intervention Results

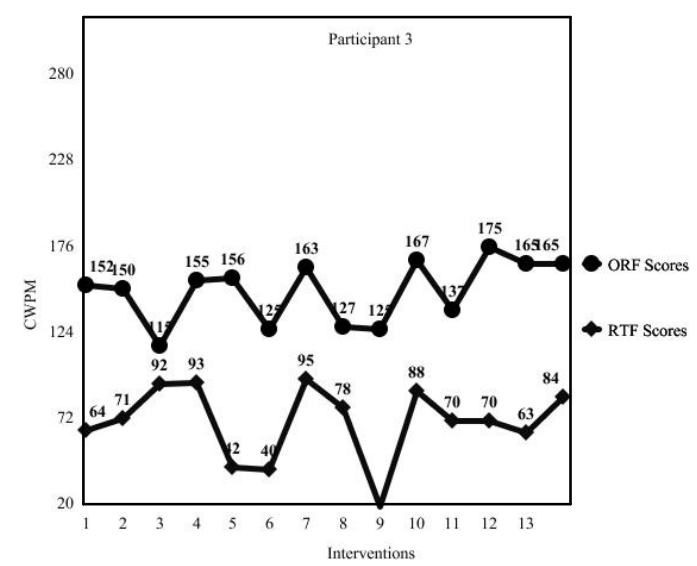

Figure 4.8 Intervention Results

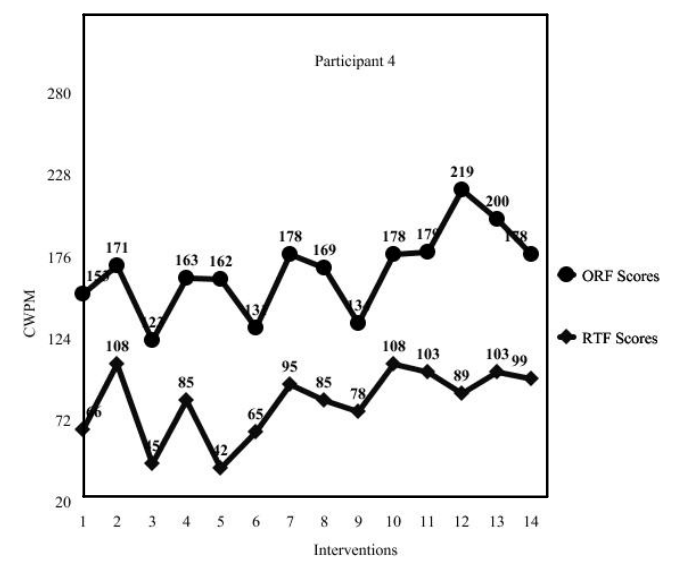

Figure 4.10 Intervention Results

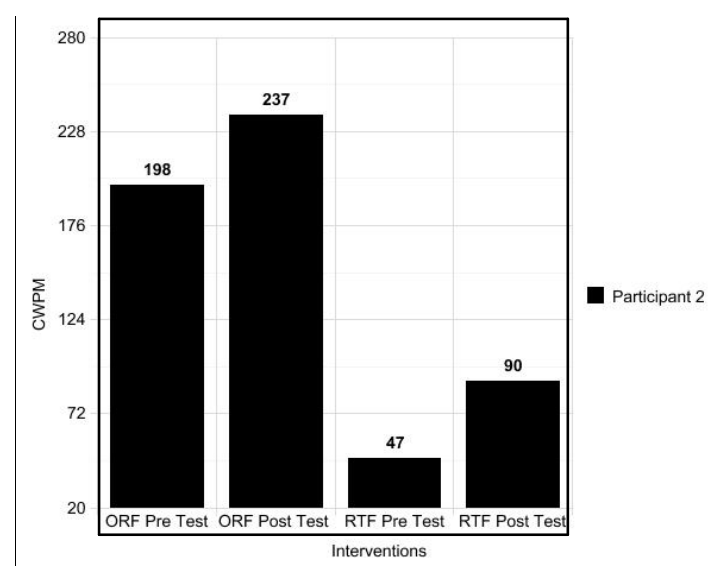

Figure 4.7 Pretest and Posttest Results

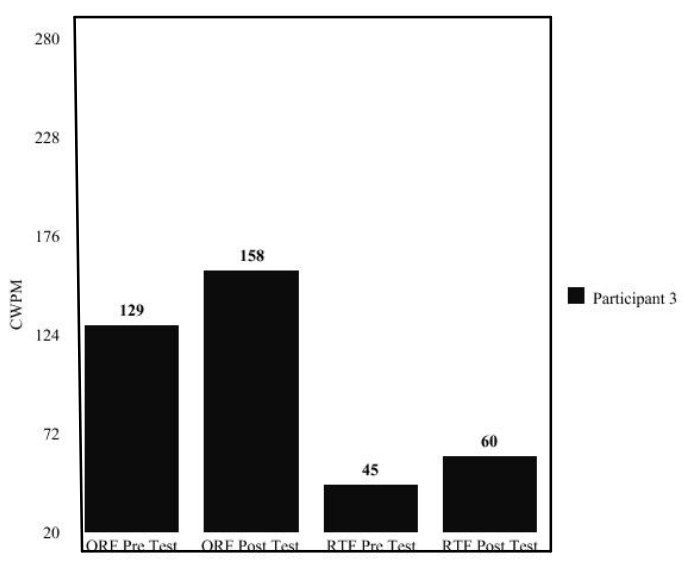

Figure 4.9 Pretest and Posttest Results

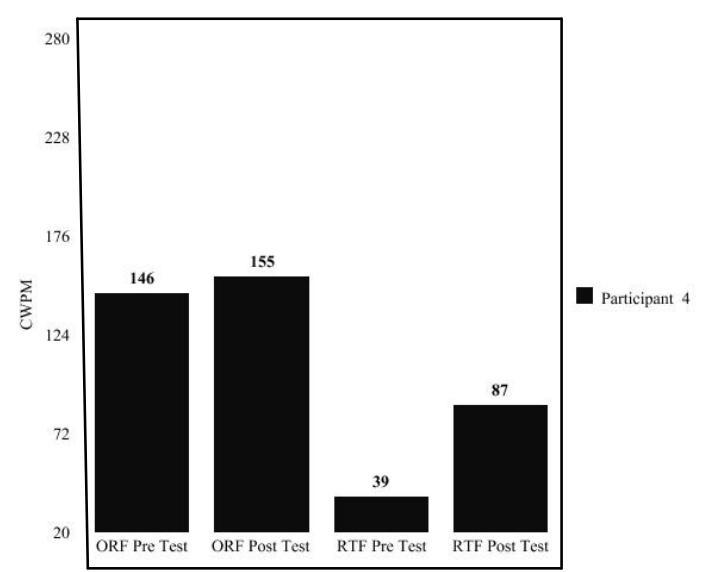

Figure 4.11 Pretest and Posttest Results 


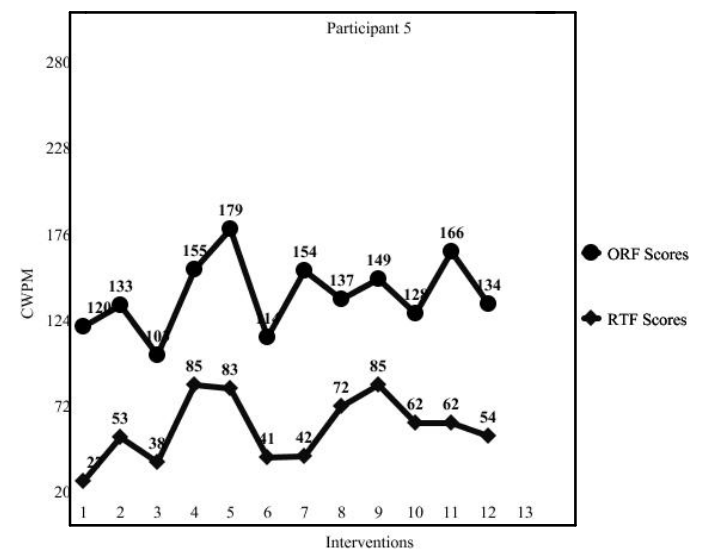

Figure 4.12 Intervention Results

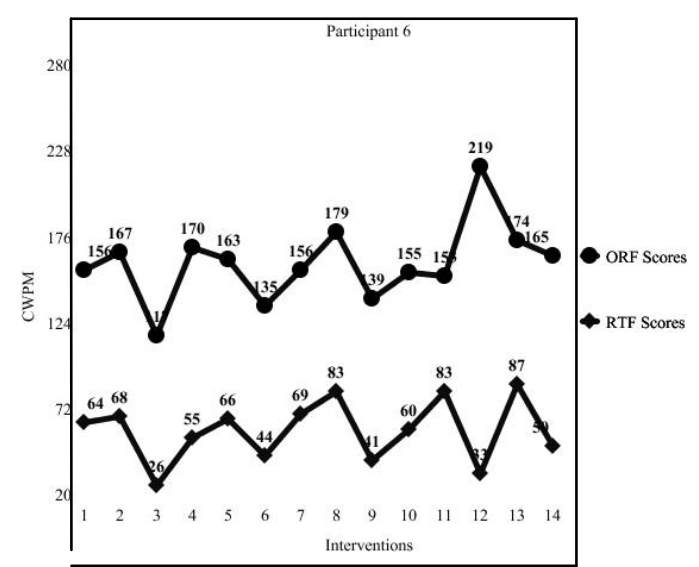

Figure 4.14 Intervention Results

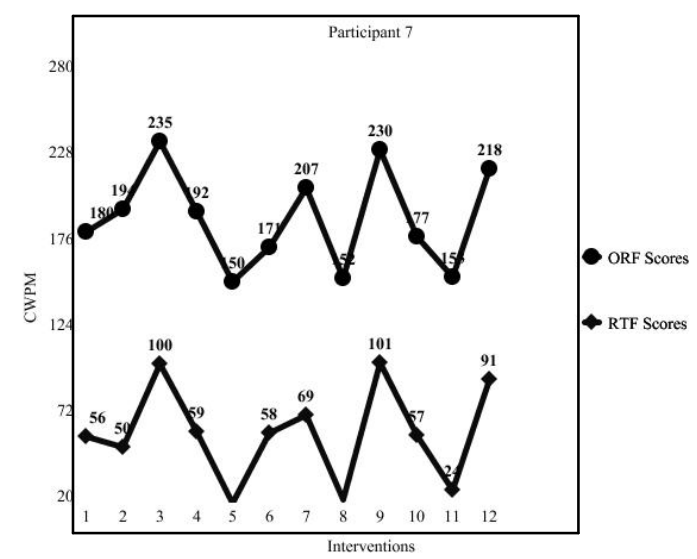

Figure 4.16 Intervention Results

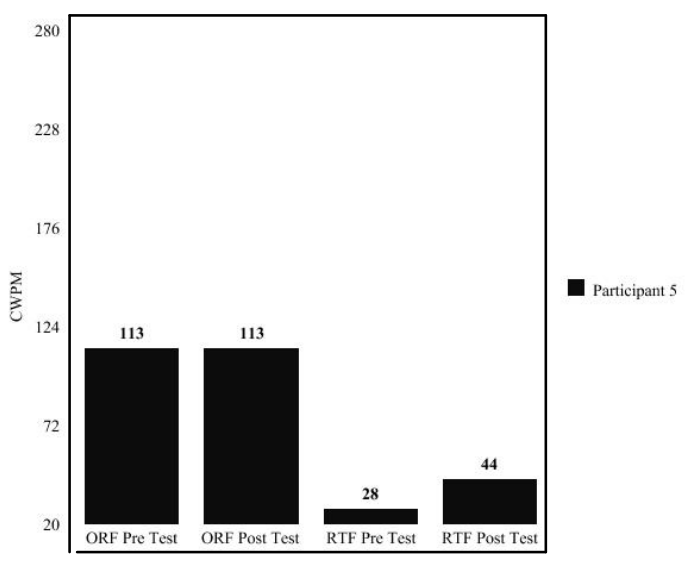

Figure 4.13 Pretest and Posttest Results

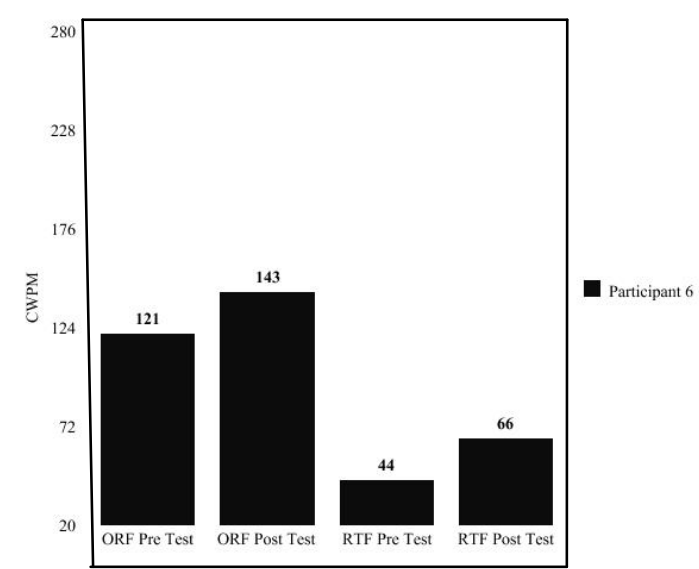

Figure 4.15 Pretest and Posttest Results

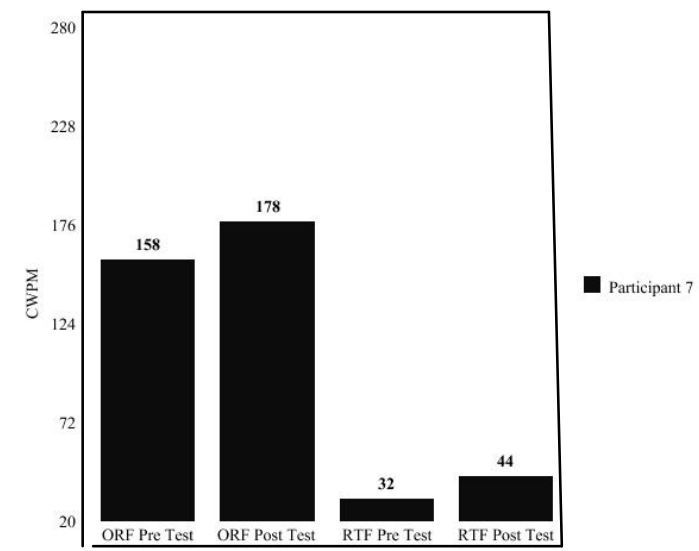

Figure 4.17 Pretest and Posttest Results 


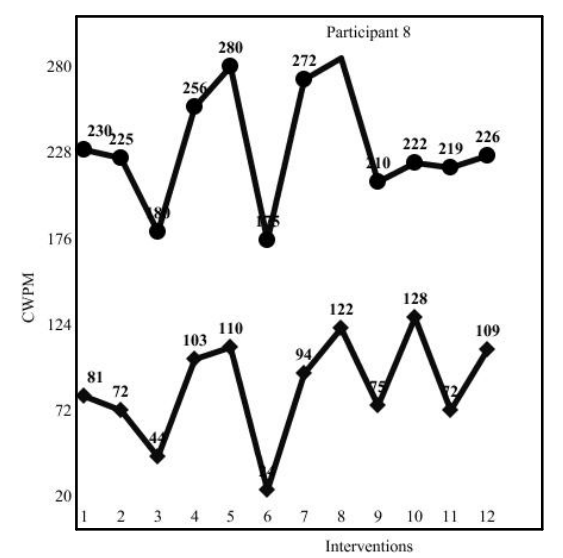

Figure 4.18 Intervention Results

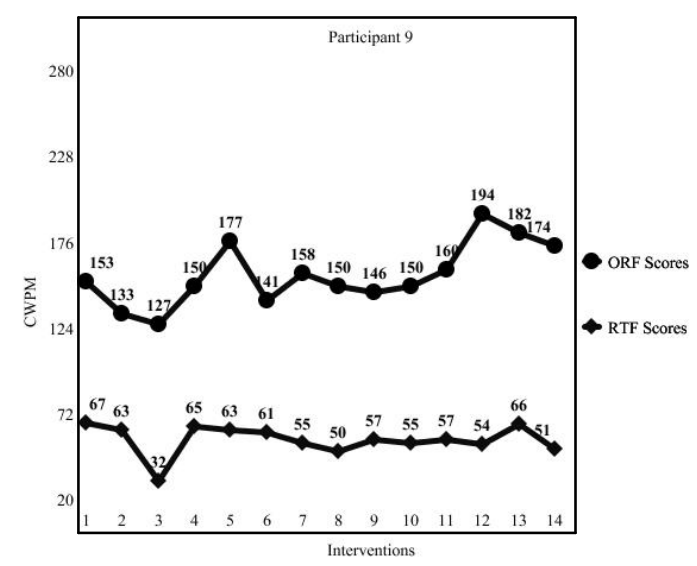

Figure 4.20 Intervention Results

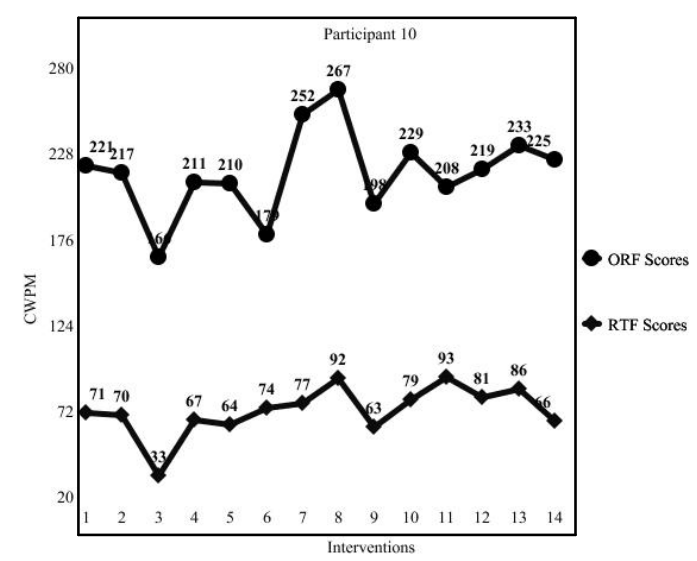

Figure 4.22 Intervention Results

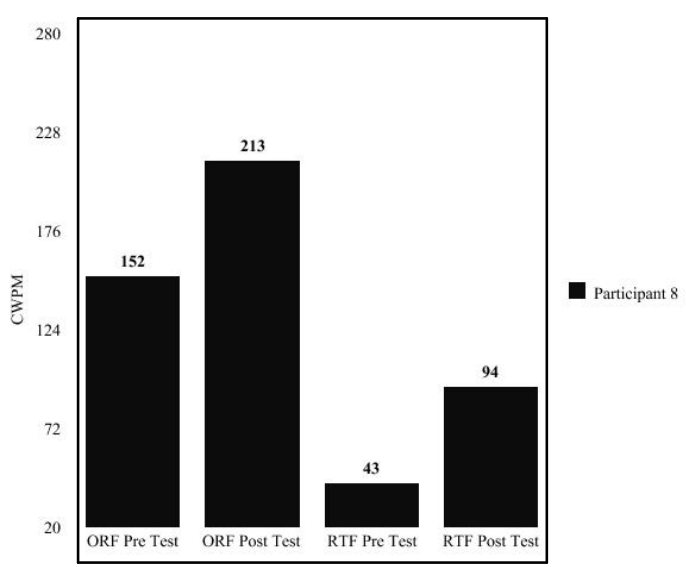

Figure 4.19 Pretest and Posttest Results

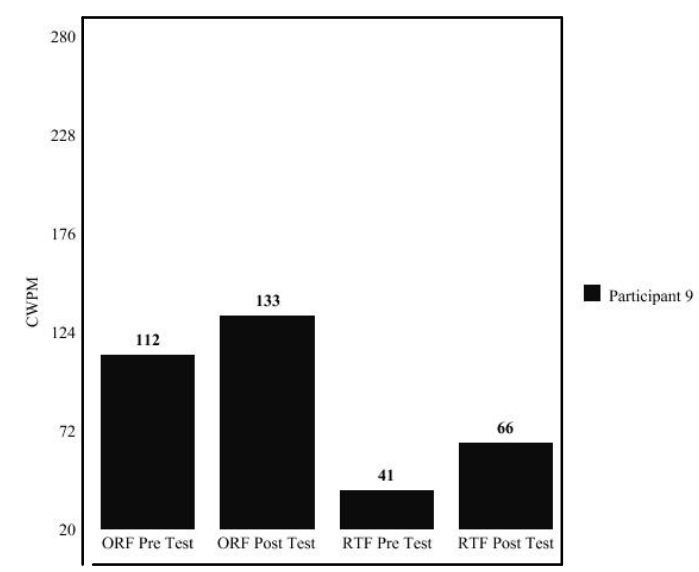

Figure 4.21 Pretest and Posttest Results

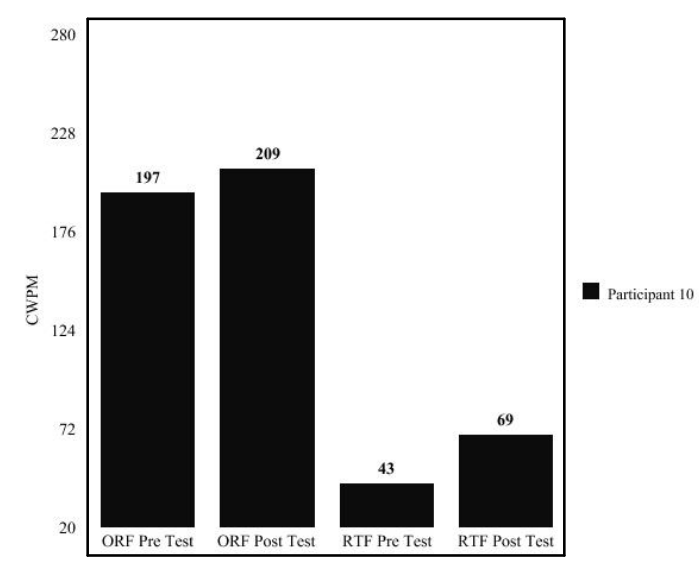

Figure 4.23 Pretest and Posttest Results 


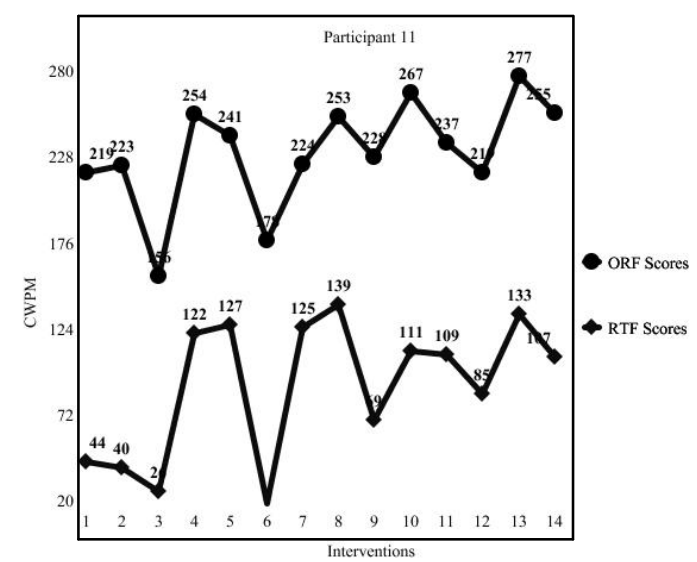

Figure 4.24 Intervention Results

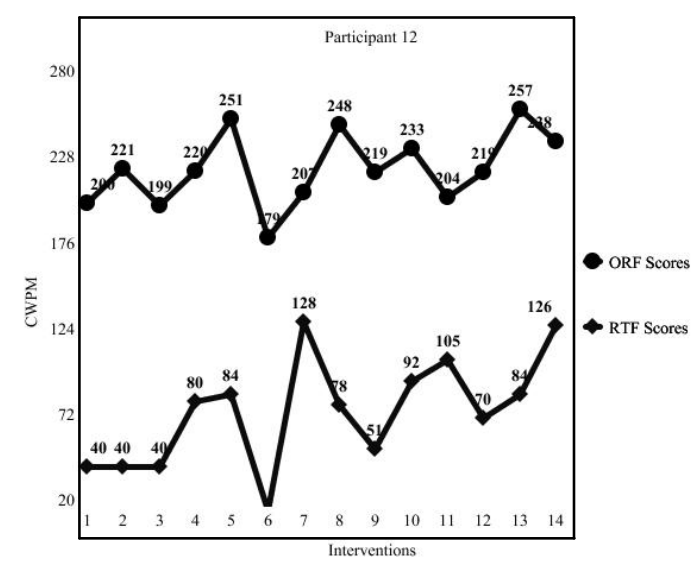

Figure 4.26 Intervention Results

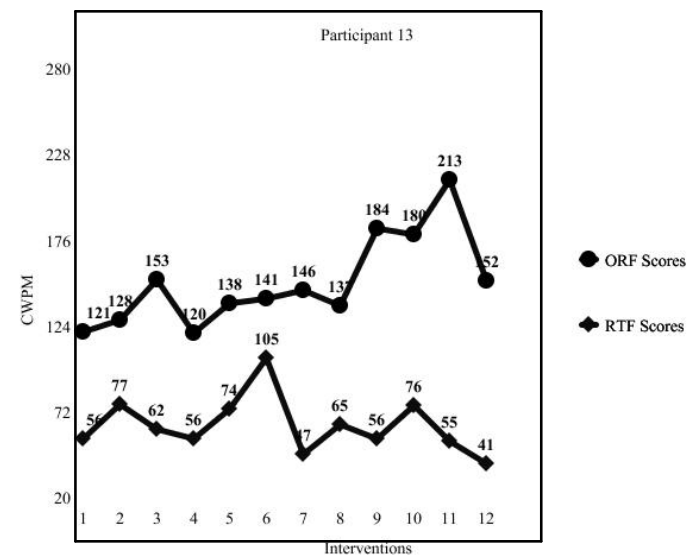

Figure 4.28 Intervention Results

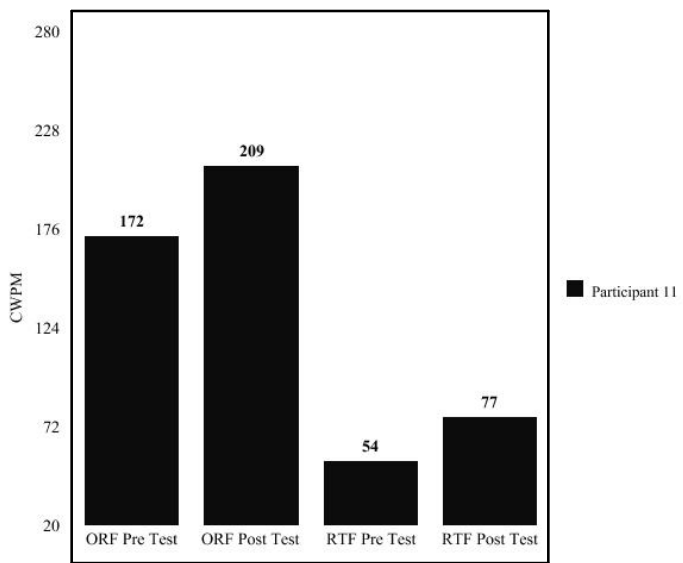

Figure 4.26 Pretest and Posttest Results

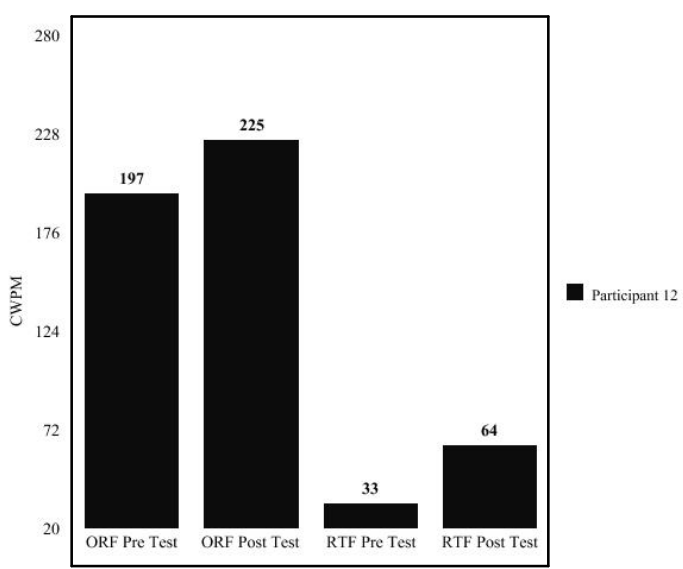

Figure 4.27 Pretest and Posttest Results

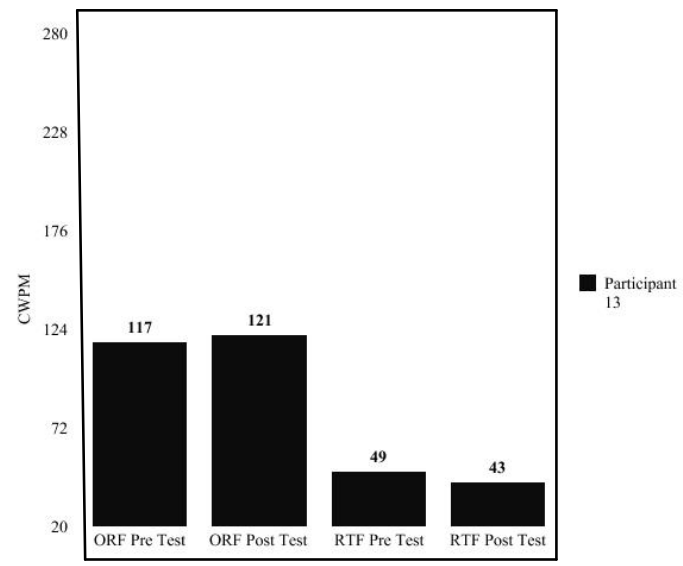

Figure 4.29 Pretest and Posttest 


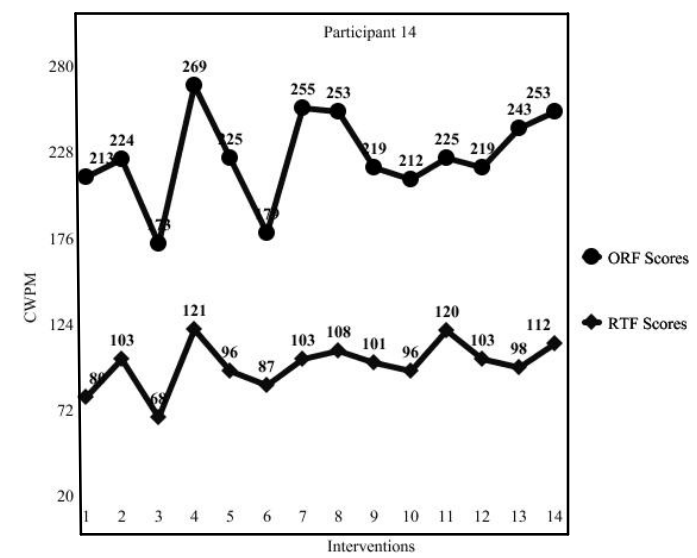

Figure 4.30 Intervention Results

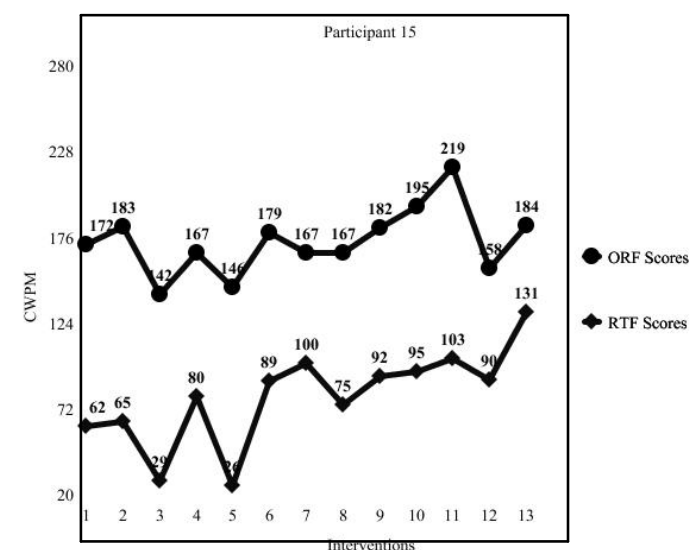

Figure 4.32 Intervention Results

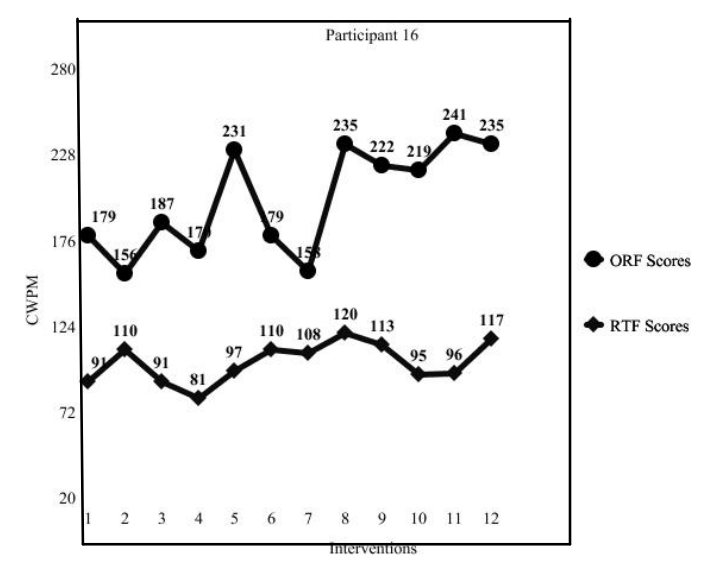

Figure 4.34 Intervention Results

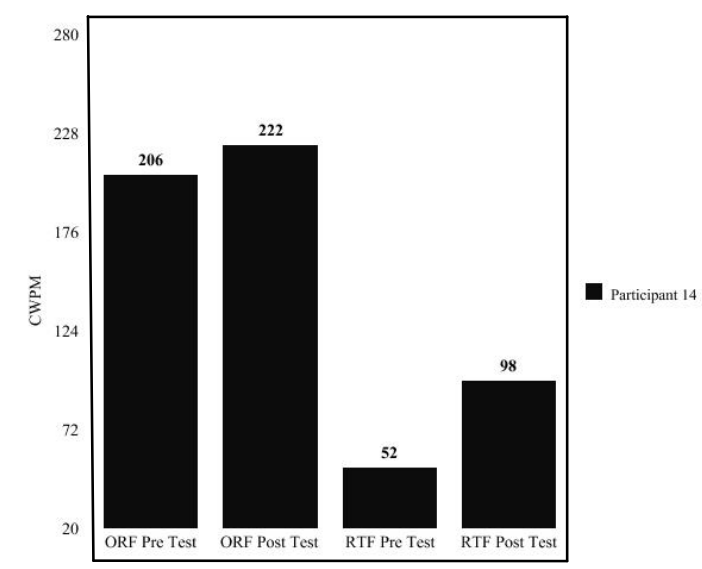

Figure 4.31 Pretest Test and Post Test

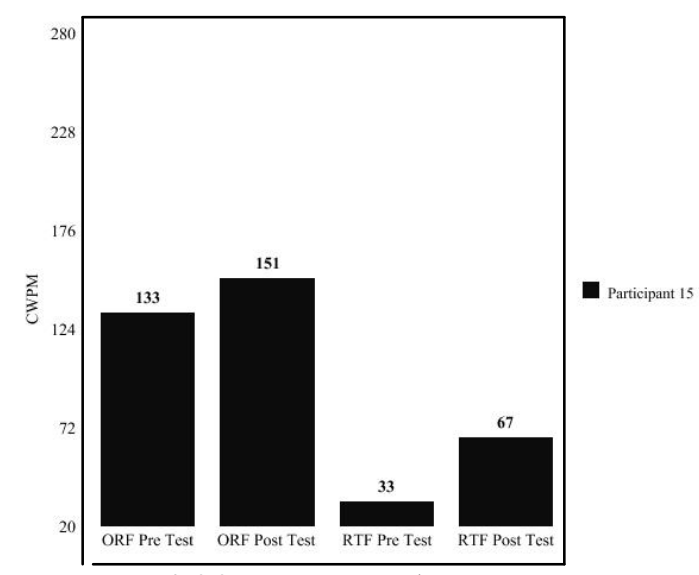

Figure 4.33 Pretest and Post Test

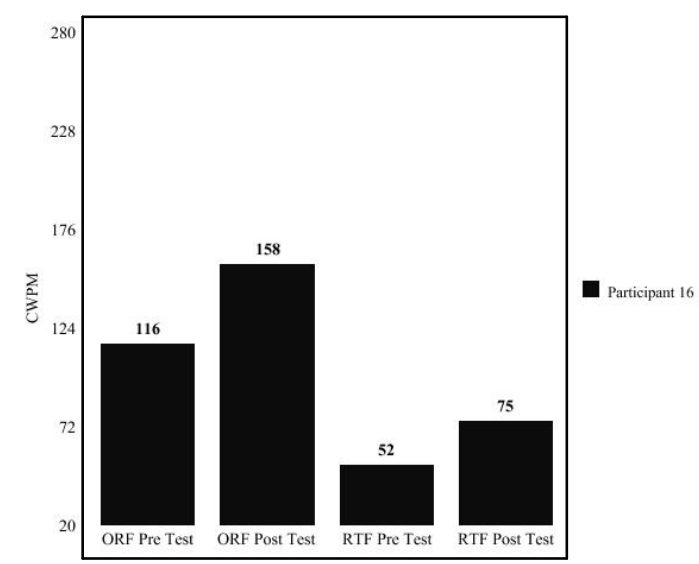

Figure 4.35 Pretest and Post Test 


\section{Conclusion}

The data indicated that the RR intervention treatments were effective in improving students' ORF by an average of 22.7 CWPM and RTF scores by an average of 29.2 CWPM, while the control group's mean ORF improvement was only 3.2 CWPM and RTF was only 5.25. I rejected the null hypotheses, which stated there was no difference in ORF and RTF between the RR group and the control group. ORF statistics indicate $t(30)=4.12, \mathrm{p}<.001$, while RTF statistics indicate $t(30)=4.58, \mathrm{p}<.001$. The data also confirmed the alternate hypotheses, which stated RR does increase ORF and RTF as compared to the control group, which received no RR interventions. The confidence level of these findings was $\mathrm{p}<.001$. The ORF effect size, as measured by $\mathrm{r}_{\mathrm{pb}}^{2}$, was .40, which was moderately significant. The RTF effect size, as measured by $\mathrm{r}_{\mathrm{pb}}^{2}$, was .44 , which was also moderately significant, further substantiated the findings. The individual results of the RR group compared to the control group further corroborated the positive benefits of RR. The individual graphs showed that students who participated in RR made positive gains in both ORF and RTF, especially as compared to the students in the control group. This research I conducted on secondary level students seems to indicate that RR improves ORF and RTF at the secondary level. The results seem to concur with the previous research--conducted mostly in the elementary grades. RR does significantly affect both a student's oral reading fluency measured in CWPM and retell fluency also measured in CWPM. 


\section{Chapter 5: Discussion and Implications}

The literature review revealed that today's secondary students are expected to read at extremely high levels. The review also suggested that many secondary students struggle with reading because they lack basic foundational reading skills, such as fluency. Students need to be fluent readers because of fluency's correlation to comprehension. According to the literature review, some secondary students still need instructional methods to increase their reading fluency. One method suggested by the research was RR. This research experiment was conducted to examine the RR method.

\section{Interpretation of Results}

I found that my research concurred with the literature review studies in a couple of areas. First, using the Hasbrouck and Tindal's 151 CWPM minimum eighth grade norms for fluency, my research found that $40 \%$ of secondary students are not fluent at minimum eighth grade standards. The evidence showed that 5 out of 16 in the control group, and 8 out of 16 in the experimental group were not initially fluent. This translates into 13 out of 32 or $40 \%$ of the students who were not at minimum fluency. This percentage is the same number that the literature reviewed deemed not proficient at the fourth grade level. Thus, this research seems to agree with the premise that perhaps middle school and high school students are not receiving fluency instruction.

Additionally, if they are not fluent in fourth grade, this suggests they may not be fluent when they graduate from high school unless changes are made in which they begin to receive direct instructional methods to improve fluency.

Second and perhaps most importantly, the data in this research concurred with the findings of the literature review that RR appears to have a significant impact on 
secondary students' ORF and RTF score. The experimental group ORF mean gain was 19.54 CWPM higher than the control group, while the experimental RTF mean gain was 23.9 more words per minute. Additionally, four out of eight or $50 \%$ of the students who started below this minimum level in the experimental group reached the minimal fluency level of $151 \mathrm{CWPM}$ after the RR interventions. On the other hand, none of the control group who started below 150 CWPM reached the minimum level on the final assessment. The experiment also revealed that student's retell improved an average of 29 words. Thus, RR benefits not only fluency, but also students' ability to retell more of what they read. Students may be able to retell more because they are read more words per minute allowing more information to be gathered. They may also retell at a higher rate because their capacity to remember what they read increased, because their ability to verbalize information increased, or because their comprehension improved.

The research also met the first goal of adding to the limited amount of research literature on the efficacy of RR on students at the secondary level. Additionally, the research seems to suggest RR method with a RTF would benefit the content area curriculum as an activity to improve fluency and comprehension in the secondary classroom.

\section{Potential Applications of the Findings}

The potential application of these findings can benefit educators and their students. First, I hope that this research spurs educators and administrators to view fluency as a serious concern for students at the secondary level for two reasons--because of its correlation to comprehension and because of its time-saving capacity for students. Multiple studies have sounded the alarm warning that $40 \%$ of students may not be fluent 
readers. I confirmed this in the small random sample that participated in my experiment, which found that $40 \%$ of the participants were below minimum eighth grade fluency levels. This should be a call to arms for educators and administrators to fight for the improvement of secondary level fluency.

Second, I hope that all educators--not just those in reading or language artsdevelop instructional methods in literacy skills, especially in fluency development. The introduction section of The Common Core State Standard Initiative (2012) clearly insisted that "instruction in reading, writing, speaking, listening and language be a shared responsibility within the school" (p. 4). Therefore, content area secondary teachers and language arts teachers must become prepared to give direct instruction in reading. Educators would benefit from a comprehensive understanding of fluency and simple fluency-building instructional methods to incorporate into their instruction.

Third, I hope that educators implement RR as one simple and efficient procedure to increase fluency. RR and other simple fluency-building methods can easily be incorporated into language arts and content-area curriculums with a limited amount of teacher training. For instance, content area teachers and language arts teachers can identify nine key topics per nine weeks and turn them into a passage of 150 or more words using the Okapi Probe Generator. They can create a RR probe on each topic so that students can partner to participate in RR once a week. Students can record each other's score and provide feedback about errors and prosody. Teachers can also preview or front load difficult vocabulary words with students before the RR. This is a common and effective vocabulary-building method. Once students become accustomed to the RR with vocabulary process, it could be a weekly activity that could be completed in 
approximately 25 minutes. Students would read the material at least three times, hear others read three times, retell two to three times, and listen to their partners retell at least two to three times. Students benefit as they develop fluency and enhance their learning with this quantity of repetition on a single topic.

\section{Biblical Integrative Component and Implications}

The research has proposed that fluency is an important component of proficient reading. Proficient reading allows individuals to gain, process, and synthesize new knowledge. A person, who reads with fluency, comprehends reading tasks required in both everyday life and academic life. I would like to propose that fluent reading and comprehension of an amazing book, the Bible, promotes a healthy spiritual life. For instance, those who can read and comprehend the Bible open their lives to God's eternal life-changing biblical power. The Bible declares this power of scripture in Hebrews 4:12 (NKJV), "For the word of God is quick, and powerful, and sharper than any two edged sword, piercing even to the dividing asunder of soul and spirit, and of the joints and marrow, and is a discerner of the thoughts and intents of the heart." This verse declares that God's word has penetrating and convicting power that helps a person supernaturally discriminate between that which is spiritual and that which is natural or fleshly. For instance, God's word convicts man of his sinful state. It also convicts man of the need to place a saving faith in the death and resurrection of Jesus Christ the Son of God. Christ's sacrificial death paid the penalty for the sin of man, and faith in Christ alone reconciles man to a right relationship with God. Once this relationship is restored God desires transformation in the life of a believer. 
A believer experiences spiritual transformation as the Holy Spirit illuminates the Bible. Arthur (2006) emphasized the transformative power of the Bible. For example, she believed when biblical teachings are applied to life, they align man's thinking to God's word. When man's thinking aligns with God's word, it brings changes to behaviors that produce transformation. She asserted the following:

If I discover what God says, understand what He means and apply that to my life, then as Romans 12:1-2 says, I'll be transformed by the renewing of my mind and be able to know what is that good and acceptable and perfect will of God. (Arthur, 2006, p. 25)

In other words, the Holy Spirit can use the Bible to renew the mind of a believer so they want what God wants, so they think like God thinks, and so they act like God desires.

The Bible not only has the power to transform, but is an amazing book in itself. First, the Bible is God's written word to man. II Timothy 3:16 (NKJV) states, "All Scripture is given by inspiration of God, and is profitable for doctrine, for reproof, for correction, for instruction in righteousness." Grudem (2000) proclaimed that all scripture is God-breathed and therefore is the Word of God in written form. He also encouraged us to ponder this thought for a moment. He asserted that there are no other written words from the "eternal, omnipotent Creator of the universe, the God who will one day judge every human being who has ever lived" (Grudem, 2000, p. 5). The God who rules and reins the whole universe has given to His creation just one book of His written words, the Bible (Grudem, 2000). Grudem also issued a relevant challenge to today's believer when he asked, "Do we act as if we really believe that 'the Bible alone, and the Bible in its entirety, is the Word of God written?" (Grudem, 2000, p. 5). The answer to this question can reveal whether a 
person possesses merely an intellectual assent to the Bible being the Word of God or a practical, deep faith displayed in everyday thoughts and actions.

Second, God obviously values reading His written word because he made sure that we have a Bible that gives a detailed record of who He is, of what He can do, of His plan for human reconciliation, and of His plan for everyday living. This amazing book "did not drop out of Heaven with a black leather cover, printed in English on paper, with 66 books bound in one volume" (Gardner, 2008b, p. 60). Torrey asserted that the 66 books of the Bible were written by 30 different men over a period of 1,500 years, and "yet in this wonderful conglomeration we find an absolute unity of thought" (Torrey, 2006). Gardner (2008b) traced the incredible history and preservation of the Bible through the ages from 586 BC, when Jewish scribes called Masorites meticulously copied the Scriptures with astounding accuracy, to the New Testament. Gardner (2008b) declared that we can trust when we read the Bible, we are reading a text that is extremely close to the original. He felt thankful for God's "providential care in preserving it through the centuries" (Gardner, 2008b, p. 101) .... and encourages us "not take this gift lightly" (Gardner, 2008b, p. 101). Torrey agreed with Gardner about God's preservation of the Bible. He asserted that from the time it was given, men have tried to destroy it, yet it still exists (Torrey, 2006). He stated the following:

“If it were man's book it would have been annihilated hundreds of years ago. But because there is in it 'the hiding of God's power' still it has fulfilled wonderfully the words of Christ, 'Heaven and earth shall pass away, but my words shall not pass away (Matthew 24:35, KJV)"' (Torrey, 2006, p. 35). 
Hence, God went to great lengths to preserve this amazing book so that we can read it today.

Third, God not only values this amazing book because of the knowledge it imparts, but also because of the relationship it builds. Relationship building is essential to the Triune God-Head. For example, Keller (2008) declared, "The doctrine of the trinity is that God is one being who exists eternally in three persons: Father, Son and Holy Spirit. The trinity means in essence that God is relational (Keller, 2008, p. 223). He also described this relationship as a dance of self-giving love in which each person exists to glorify and rejoice in the other. God created humans to share in this type of selfgiving relationship. Keller claimed that humans were made for "mutually self-giving, other-directed love" (Keller, 2008, p.p. 226). He also affirmed that men were created with the ability to communicate just as the three persons of the trinity fellowship and communicate.

Consequently, God imparts to humans the Word or the Bible as a written form of communication and fellowship with himself. Men constantly use God's written language to understand what God desires for their lives. Personal discipleship, as well as reconciliation and discipleship of others, depends on reading, believing and obeying God's written word. Gardner (2008a) stated humans are dependent upon God's word for answers to life's most basic questions about origin, purpose, destiny, life and death. He believed that man, science and philosophy are not without mistakes as they attempt to answer these questions. He declared that only the Bible has true answers to life's basic questions as he states the following: 
The only way we can have certain truth on issues is for God to disclose to us truths about ultimate issues. The Bible is not human speculation in an errormarred search for God. Scripture discloses himself and his will in the story of human history." (Gardner, 2008a, p. 60)

God not only reveals the answers to life's basic questions through the Bible, but also communicates His desire for a personal relationship through this amazing book.

Lastly, I am thankful to the Lord, who is the Creator of the earth, for giving to man His written word. It contains many commands and promises that are all meant to strengthen man's relationship with the God-head. For instance, the command "to fill the earth and subdue it" (Gen. 2:15), encourages humans to discover ways to add value to human life so that they can fulfill God's purposes, one of which is to bring Him glory. Baumann (2011) suggested "this adding value or developing the resources of the creation (including human talents and abilities) would include the creation of art, music, literature, architecture, science, technology, and so forth, which would be useful to fulfill the purpose of God" (Baumann, 2011, p. 117). Therefore, educators who help develop students' reading talents and abilities, including fluency and comprehension, add value to the lives of their students. God's initial command to man also included the mandate to be stewards of the earth. Baumann claimed that proper stewardship is to use your talents in ways that show the love of God toward others (Baumann, 2011). Educators encounter multiple opportunities each day to show God's love as they interact with students and fellow educators. Furthermore, humanity also engages in stewardship as they discover the laws that God has placed into the universe (Baumann, 2011). Research is one way that can be used to discover the laws that God has placed into the universe and to add 
value to the lives of others because it helps us to discover tendencies and instructional methods that can benefit others. I can use the results of this research to benefit others and add value to their lives.

\section{Strengths of Study}

The strengths of this study are threefold. First, the literature review discussed many aspects of fluency: its many definitions, its link to comprehension, its importance at the secondary level, its lack of attention at the secondary level, and its need for developmental instructional methods. This review set the stage for the experiment. Next, the data significantly supported the alternate hypothesis that RR interventions would positively enhance ORF and RTF. Finally, the implications for the secondary curriculum are enlightening. Students need instruction in fluency, and this paper gave some easy, effective methods of implementing this into the content area curriculum.

\section{Limitations}

Only GPAs of the two groups were verifiable; the IQ of the two groups could not be verified due to lack of data on all individuals in this area. Therefore, this could be a confounding variable. Additionally, the sample size consisted of only 16 in each group so the power of the experiment could have been increased with a larger sample size. The inter-rater reliability demonstrated what the literature review stated about the difficulty of correctly recording the number of words in a retell. As the evidence shows the partners had difficulty correctly recording the number of words in the retell during the practice sessions, however, they were accurate in the ORF. 


\section{Suggestions for future research}

Future research recommendations echo the sentiments of previous researchers in this area of secondary fluency. A need exists for more research and more data on valuable methods of developing secondary students' fluency. Adding a quantitative survey or questionnaire to determine the student's perception of the benefits of RR could provide more insights into its perceived value by the students themselves. More practice before the actual interventions to ensure students ability to record retells accurately would also be recommended for future research. Perhaps a school wide teacher survey to determine teachers' understanding of fluency, its importance, and methods they use, if any, to develop it. Finally, teacher input into important topics for the creation of RR nonfiction, expository passages might also be beneficial to future research and to implementing RR into the content area curriculum. 


\section{References}

Ardoin, S. P., Eckert, T. L., \& Cole, C. S. (2008). Promoting generalization of reading: A comparison of two fluency-based interventions for improving general education student's oral reading rate. Journal of Behavioral Education, 17(3), 237-252. doi:10.1007/s10864-008-9066-1

Ari, O. (2011). Fluency interventions for developmental Readers: Repeated readings and wide reading. Research \& Teaching in Developmental Education, 28(1), 5-15.

Arthur, K. (2006). What does the Bible say? A conversation with Kay Arthur. Decision, 47, 25-27.

Baumann, E. K., (2011). Worldview as worship: The dynamics of a transformative Christian education. Eugene, OR: Wipf and Stock.

Begney, J. C., Krouse, H. E., Ross, S. G., \& Mitchell, R. C., 2009. Increasing elementary-aged students' reading fluency with small-group interventions: A comparison of repeated reading, listening passage preview, and listening only strategies. Journal of Behavior Education. 18(3), 221-228. doi:10.10007/s10864099-9090-9

Bellinger, J. M., \& DiPerna, J. C. (2011). Is fluency-based story retell a good indicator of reading comprehension? Psychology in the Schools, 48(4), 416-426. doi:10.1002/pits.20563

Cahill, M. A., \& Gregory, A. E., (2011). Putting the fun back into fluency. The Reading Teacher, 65(2), 127-131. doi:10.1002/TPTR01018

Carnine, D. W., Silbert, J., Kame'enui, J., Tarver, S. G. (2010). Reading development: Chall's Model. Pearson Allyn Bacon Prentice Hall. Retrieved from 
THE EFFICACY OF REPEATED READING

http://www.education.com/reference/article/Chall-model-reading-development/ Common Core State Standard Initiative. (2012). Common Core Standard for English Language Arts \& Literacy in History/Social Studies, Science, and Technical Subjects. Washington DC: The National Governors Association Center for Best Practices and the Council of Chief State School Officers. Retrieved June 10, 2013 from http://www.corestandards.org/assets/CCSSI_ELA\%20Standards.pdf

Evanchan, G. (2010). Fluency is a vital link in the comprehension chain. Ohio Reading Teacher, 40(1), 11-18.

Gardner H. L. (2008a). How God's word has come to us: God's word written. Christian Standard, 143, 60-62.

Gardner H. L. (2008b). How God's word has come to us: God's word preserved. Christian Standard, 14, 98-101.

Gorsuch, G., \& Taguchi, E. (2010). Developing reading fluency and comprehension using repeated reading: Evidence from longitudinal student reports. Language Teaching Research, 14(1), 27-59. doi:10.1177/1362168809346494

Grudem, W. A. (2000). Do we act as if we really believe that "the Bible alone, and the Bible in its entirety, is the word of god written?". Journal of the Evangelical Theological Society, 43(1), 5-26.

Hasbrouck, J., \& Tindal. G. A. (2006). Oral reading fluency norms: A valuable assessment tool for reading teachers. International Reading Association, 59(7), 636-644. doi:10.1598/RT.59.7.3 
Hawkins, R. O., Hale, A., Sheeley, W., \& Ling, S. (2011). Repeated reading and vocabulary-previewing interventions to improve fluency and comprehension for struggling high-school readers. Psychology in the Schools, 48(1), 59-77.

Hiebert, E. H., Samuels, S. J., Rasinski, T. V. (2012) Comprehension-based student reading rates: What do we know? what do we need to know? Literacy Research \& Instruction, 51(2) 110-124.

Hiebert, E. H. \& Pearson, P. (2012). What happens to the basics? Educational Leadership, 70(4), 48-53.

Hudson, R. F., Pullen, P. C., Lane, H. B., \& Torgesen, J. K. (2009). The complex nature of reading fluency: A multidimensional view. Reading \& Writing Quarterly, 25(1), 4-32. doi:10.1080/10573560802491208

Klauda, S. L., \& Guthrie, J. T. (2008). Relationship of three components of reading fluency to reading comprehension. Journal of Educational Psychology, 100(2) 310-321.

Keller, T. (2008). The reason for God. New York, NY: Penguin Group. Kostewicz, D. E. (2012). Implementing systematic practice to build reading fluency via repeated readings. New England Reading Association Journal, 47(2), $17-22$.

Kuhn, M. R., Schwanenflugel, P. J., Meisinger, E. B., Levy, B. A., \& Rasinski, T. V. (2010). Aligning theory and assessment of reading fluency: Automaticity, prosody, and definitions of fluency. Reading Research Quarterly, 45(2), 230-251. 
Lo, Y., Cooke, N. L., \& Starling, A. L. (2011). Using a repeated reading program to improve generalization of oral reading fluency. Education and Treatment of Children, 34(1), 115-140.

Marchand-Martella, N., Martella, R. C., Orlob, M., \& Ebey, T. (2010). Conducting action research in a rural high school setting using peers as corrective reading instructors for students with disabilities. Rural Special Education Quarterly, 29(4), 5-13.

McCallum, S. R., Krohn, K. R., Skinner, C. H., Hilton-Prillhart, A. A., Hopkins, M., Waller, S. F., \& et al. (2011). Improving reading comprehension of at-risk highschool students: The art of reading program. Psychology in Schools, 48(1), 78-86.

McComas, J., Wagner, D., Chaffin, M., Holton, E., McDonnell, M., \& Monn, E. (2009). Prescriptive analysis: Further individualization of hypothesis testing in brief experimental analysis of reading fluency. Journal of Behavioral Education, 18(1), 56-70.

Murray, M. S., Munger, K. A., \& Clonan, S. M. (2012). Assessment as a strategy to increase oral reading fluency. Intervention in School and Clinic, 47(3), 144-151.

National Center for Education Statistics. (2009). The nation's report card. Reading 2009: National Assessment of Educational Progress at grades 4 and 8 (NCES 2010-458). Washington DC: Institute of Education Sciences Retrieved June 6, 2013 from http://nces.ed.gov/nationsreportcard/pdf/main2009/2010458.pdf

National Center for Education Statistics., (2010). Common core of data for Unioto high school. Washington, DC: Institute of Education Sciences, U.S. Department of Education. Retrieved May 19, 2013 from http://nces.ed.gov/ccd/schoolsearch/school_ 
National Center for Education Statistics. (n.d.). Create a Graph. Washington, DC: Institute of Education Sciences, U.S. Department of Education. Retrieved July1, 2013 from http://nces.ed.gov/nceskids/createagraph/default.aspx

Nichols, W. D., Rupley, W. H., \& Rasinski, T. (2009). Fluency in learning to read for meaning: Going beyond repeated readings. Literacy Research and Instruction, $48(1), 1-13$.

O'Keeffe, B. V., Slocum, T. A., Burlingame, C., Snyder, K., \& Bundock, K. (2012). Comparing results of systematic reviews: Parallel reviews of research on repeated reading. Education \& Treatment of Children (West Virginia University Press), 35(2), 333-366.

Paige, D. D., Rasinski, T.V., \& Magpuri-Lavell, T. (2012). Is fluent, expressive reading important for high school readers? Journal of Adolescent \& Adult Literacy, 56(1), $67-76$.

Rasinski, T., Rikli, A., Johnston, S. (2009). Reading fluency: More than automaticity? more than a concern for the primary grades? Literacy Research and Instruction, 48(4), 350-356.

Rasinski, T. (2010). Assessing reading fluency. Hawaii: Pacific Resources for Education and Learning. Retrieved from http://www.prel.org/products/re_/assessingfluency.htm.

Rasinski, T., Samuels, S., Hiebert, E., Petscher, Y., \& Feller, K. (2011). The relationship between a silent reading fluency instructional protocol on students' reading comprehension and achievement in an urban school setting. Reading Psychology, 32(1), 75-97. doi:10.1080/02702710903346873 
Rasinski, T. V. (2012). Why reading fluency should be hot. Reading Teacher, 65(8), 516-522. doi:10.1002/TRTR.01077

Reutzel, D. R., Fawson, P. C., \& Smith, J. A. (2008). Reconsidering silent sustained reading: An exploratory study of scaffolded silent reading. Journal of Educational Research 102(1), 37-50.

Roberts, G., Torgesen, J. K., Boardman, A., \& Scammacca, N. (2008). Evidence-based strategies for reading instruction of older students with learning disabilities. Learning Disabilities Research \& Practice, 23(2), 63-69. doi:10.1111/j.15405826.2008.00264.x

Roehrig, A.D., Petscher Y., Nettles, S.M., Hudson R. F., \& Torgesen, J.K. (2008). Accuracy of the DIBELS oral reading fluency measure for predicting third grade reading comprehension outcomes. Journal of Psychology, 46(3), 343-366. doi:10.1016/j.jsp.2007.06.006.

Samuels, J. (2006). Looking backward: Reflections on a career in reading. Journal of Literacy Research, 38(3), 327-344.

Shanahan, T. (2006). The National reading panel report: Practical advice for teachers. University of Illinois at Chicago, Retrieved from http://www.learningpt.org/pdfs/literacy/nationalreading.pdf p. 1-44.

Soper, D. S. (2013). Effect Size (Cohen's d) Calculator for a Student t-Test [Software]. Retrieved June 30, 2013 from http://www.danielsoper.com/statcalc

Stanovich, K. E. (2008). Matthew effects in reading: Some consequences of individual differences in the acquisition of literacy. Journal of Education 189(1), 23-57. 
Therrien, W. J., Kirk, J. F., \& Woods-Groves, S. (2012). Comparison of a reading fluency intervention with and without passage repetition on reading achievement. Remedial \& Special Education, 33(5), 309-319. doi:10.1177/0741932511410360

Torrey, R. A. (2006). Why the Bible is God's word. Decision, 47, 34-35.

Urbaniak, G. C., \& Plous, S. (2013). Research Randomizer (Version 4.0) [Computer software]. Retrieved June 22, 2013, from http://www.randomizer.org/

Vadasy, P. F., \& Sanders, E. A. (2008). Repeated reading intervention: Outcomes and interactions with readers' skills and classroom instruction. Journal of Educational Psychology, 100(2), 271-290. doi:10.1037/0022-0663.100.2.272

Wexler, J., Vaughn, S., Roberts, G., \& Denton, C.A. (2010). The efficacy of repeated reading and wide reading practice for high school students with severe reading disabilities. Learning Disabilities Research \& Practice, 25(1), 2-10. 
Appendix A

Description of the Process Gathering of CBM/ORF Data taken from Rasinski (2010)

1. Find a passage(s) of approximately 250 words written at the student's independent or instructional level. Submit the passage to a text readability formula to estimate its appropriateness.

2. Ask the student to read the passage for one minute and tape-record the reading. Emphasize that the text should be read aloud in a normal way, and not faster than normal.

3. Mark any uncorrected errors made by the student. Errors include mispronunciations, substitutions, reversals, omissions, or words pronounced by the examiner after a wait of 2-3 seconds without an attempt or response from the student. Mark the point in the text the student has come to after one minute of reading.

4. Repeat steps 1 and 2 with the same passage. You can use the median or middle score or a mean average of the three.

5. Determine accuracy by dividing the number of words read correctly per minute (CWPM) by the total number of words read $(\mathrm{CWPM}+$ any uncorrected errors). This number will be a percentage.

Determine the rate by calculating the total number of CWPM and comparing the student's performance against the target norms. 


\section{Appendix B}

Sample CBM Reading Passage Probe Created from OKAPI Generator

\section{\# 9 Forms of Government}

A monarchy is a form of government in which the office

of head of state is usually held until death or

abdication, is most often hereditary, and usually accords

official pre-eminence to members of the reigning dynasty.

The monarch often bears the title king or queen. However,

Emperor/empress, grand duke/grand duchess, prince/princess

"single ruler, traditionally heads of state bearing

the title president or premier are not officially considered

monarchs. A dictator is a ruler, who assumes sole and 
titular uses. In modern, usage, the term "dictator" is 191

generally used to describe a leader who holds and/or 200

abuses an extraordinary amount of personal power, $\quad 207$

especially the power to make laws without effective 215

restraint by a legislative assembly. $\quad 220$

Spache Readability Formula for This Passage $=(0.141 * 24.44$ Avg. Number of Words Per Sentence) $(0.086 * 34.09$ Percent of Words in Sample Not Found on Spache Revised Word List $)+0.839=7.21$ Grade Equivalent 
THE EFFICACY OF REPEATED READING

\section{Appendix C}

Sample Score Sheet Used for Interventions

\# 9 Forms of Democracy (expository)

Total Words Read

Miscues

CWPM Total Words Retold

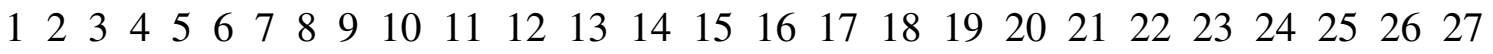
$\begin{array}{llllllllllllllllllllllll}28 & 29 & 30 & 31 & 32 & 33 & 34 & 35 & 36 & 37 & 38 & 39 & 40 & 41 & 42 & 43 & 44 & 45 & 46 & 47 & 48 & 49 & 50 & 51\end{array}$

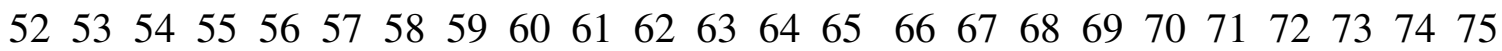
$\begin{array}{llllllllllllllllllllllll}76 & 77 & 78 & 79 & 80 & 81 & 82 & 83 & 84 & 85 & 86 & 87 & 88 & 89 & 90 & 91 & 92 & 93 & 94 & 95 & 96 & 97 & 98 & 99\end{array}$ $100101102103104105106107108 \quad 109110111112113 \quad 114 \quad 115116117$ $\begin{array}{llllllllllllllllll}118 & 119 & 120 & 121 & 122 & 123 & 124 & 125 & 126 & 127 & 128 & 129 & 130 & 131 & 132 & 133 & 134 & 135\end{array}$ $\begin{array}{llllllllllllllllll}136 & 137 & 138 & 139 & 140 & 141 & 142 & 143 & 144 & 145 & 146 & 147 & 148 & 149 & 150 & 151 & 152 & 153\end{array}$ $\begin{array}{llllllllllllllllll}154 & 155 & 156 & 157 & 158 & 159 & 160 & 161 & 162 & 163 & 164 & 165 & 166 & 167 & 168 & 169 & 170 & 171\end{array}$ $\begin{array}{lllllllll}172 & 173 & 174 & 175 & 176 & 177 & 178 & 179 & 180\end{array}$

\#10 Saving a Life (fiction)

Total Words Read

Miscues CWPM Total Words Retold

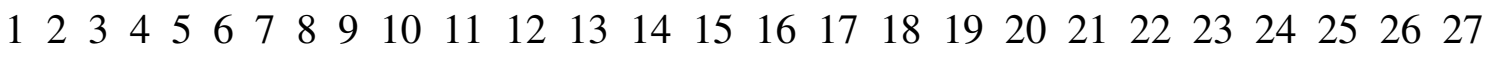
$\begin{array}{llllllllllllllllllllllll}28 & 29 & 30 & 31 & 32 & 33 & 34 & 35 & 36 & 37 & 38 & 39 & 40 & 41 & 42 & 43 & 44 & 45 & 46 & 47 & 48 & 49 & 50 & 51\end{array}$

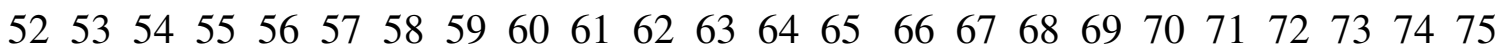
$\begin{array}{llllllllllllllllllllllll}76 & 77 & 78 & 79 & 80 & 81 & 82 & 83 & 84 & 85 & 86 & 87 & 88 & 89 & 90 & 91 & 92 & 93 & 94 & 95 & 96 & 97 & 98 & 99\end{array}$ $100101102103104105106107108109110111112 \quad 113 \quad 114 \quad 115116117$ $\begin{array}{llllllllllllllllll}118 & 119 & 120 & 121 & 122 & 123 & 124 & 125 & 126 & 127 & 128 & 129 & 130 & 131 & 132 & 133 & 134 & 135\end{array}$ $\begin{array}{llllllllllllllllll}136 & 137 & 138 & 139 & 140 & 141 & 142 & 143 & 144 & 145 & 146 & 147 & 148 & 149 & 150 & 151 & 152 & 153\end{array}$ 


\section{Appendix D}

\section{List of Pretest and Posttest Procedures}

The following directions were read verbatim every time:

1. "Please read in a manner that allows you to read as quickly as possible and at the same time allows you to remember as much as possible."

2. Holds clipboard and stopwatch so child cannot see what is scored.

3. Starts stopwatch after student reads the first word.

4. Follow along and scores as child reads.

5. Slashes incorrect words according to scoring rules.

6. At the end of 1 minute, says "stop" and puts a / after the last word read.

7. Records the number of words read minus the number of words read incorrectly in 1 minute for the ORF score.

8. Gives the following directions verbatim every time: "Please tell me all about what you just read. Try to tell me everything you can remember."

9. Starts the stopwatch after student says the first word.

10. Records each word that describes the content of the story.

11. At the end of one minute, says, "stop."

12. Records the total number of words in the RTF. 


\section{Appendix E}

ORF Individual Mean Initial, Mean Final, and Difference

\begin{tabular}{|l|l|l|l|l|l|l|l|}
\hline $\begin{array}{l}\text { Control } \\
\text { Group }\end{array}$ & & & & $\begin{array}{l}\text { RR } \\
\text { Group }\end{array}$ & & & \\
\hline Student & Initial & Final & Difference & Student & Initial & Final & Difference \\
\hline 1 & 183.3 & 189.6 & 6.3 & 5 & 113 & 113 & 0 \\
\hline 2 & 108.7 & 97.3 & -11.4 & 13 & 117 & 120.7 & 3.7 \\
\hline 3 & 118 & 119.7 & 1.7 & 14 & 205.7 & 221.7 & 16 \\
\hline 4 & 132.3 & 145.6 & 13.3 & 15 & 133.3 & 150.7 & 17.4 \\
\hline 5 & 164.7 & 163.7 & -1 & 16 & 116 & 158 & 42 \\
\hline 6 & 173 & 162.3 & -10.7 & 1 & 242 & 247.3 & 5.3 \\
\hline 7 & 213 & 198.7 & -14.3 & 4 & 145.7 & 155.3 & 9.6 \\
\hline 8 & 120 & 136.3 & 16.3 & 9 & 112 & 133.3 & 21.3 \\
\hline 9 & 161 & 168.7 & 7.7 & 10 & 197.3 & 209 & 11.7 \\
\hline 10 & 98 & 106 & 8 & 11 & 171.7 & 209.3 & 37.6 \\
\hline 11 & 172.7 & 178.8 & 6 & 2 & 197.7 & 237 & 39.3 \\
\hline 12 & 173.7 & 191.6 & 17.9 & 3 & 129.3 & 158 & 28.7 \\
\hline 13 & 195 & 199.3 & 4.3 & 8 & 152 & 213 & 61 \\
\hline 14 & 235 & 227 & -8 & 12 & 196.7 & 224.7 & 28 \\
\hline 15 & 205.7 & 216.3 & 10.6 & 6 & 121 & 143 & 22 \\
\hline 16 & 210 & 214 & 4 & 7 & 158.3 & 178.3 & 20 \\
\hline Ave & 166.5 & 169.7 & 3.2 & & 156.8 & 179.5 & 22.7 \\
\hline Std & 18.9 & 17.3 & 9.9 & & 40.6 & 43.4 & 16.2 \\
\hline
\end{tabular}

t-Test: Two-Sample Assuming Unequal Variances

\begin{tabular}{lrr}
\hline & CONT & EXP. \\
& ORF & ORF \\
\hline Mean & 3.16875 & 22.725 \\
Variance & 97.6663 & 263.69 \\
Observations & 16 & 16 \\
Hypothesized Mean Difference & 0 & \\
df & 25 & \\
t Stat & -4.1151 & \\
P(T<=t) one-tail & 0.00018 & \\
t Critical one-tail & 1.70814 & \\
P $(\mathrm{T}<=\mathrm{t})$ two-tail & 0.00037 & \\
t Critical two-tail & 2.05954 & \\
\hline
\end{tabular}




\section{Appendix F}

RTF Individual Mean Initial, Mean Final, and Difference

\begin{tabular}{|l|l|l|l|l|l|l|l|}
\hline $\begin{array}{l}\text { Control } \\
\text { Group }\end{array}$ & & & & $\begin{array}{l}\text { RR } \\
\text { Group }\end{array}$ & & & \\
\hline Student & Initial & Final & Difference & Student & Initial & Final & Difference \\
\hline 1 & 30 & 45.6 & 15.6 & 5 & 28.3 & 44 & 15.7 \\
\hline 2 & 31.3 & 32.7 & 1.4 & 13 & 49.3 & 42.6 & -6.7 \\
\hline 3 & 67 & 69.7 & 2.7 & 14 & 51.7 & 98.3 & 46.6 \\
\hline 4 & 62.7 & 42 & -20.7 & 15 & 33 & 66.7 & 33.7 \\
\hline 5 & 12 & 17.3 & 5.3 & 16 & 51.7 & 75 & 23.3 \\
\hline 6 & 26.7 & 36.3 & 9.6 & 1 & 51.7 & 110 & 58.3 \\
\hline 7 & 36 & 27.3 & -8.7 & 4 & 39.3 & 87 & 47.7 \\
\hline 8 & 30.3 & 50 & 19.7 & 9 & 41 & 66 & 25 \\
\hline 9 & 20.3 & 35 & 14.7 & 10 & 43 & 68.7 & 25.7 \\
\hline 10 & 39.7 & 49.7 & 10 & 11 & 54 & 77.3 & 23.3 \\
\hline 11 & 41.7 & 50.3 & 8.6 & 2 & 46.7 & 90 & 43.3 \\
\hline 12 & 45.3 & 47.6 & 2.3 & 3 & 44.7 & 60 & 15.3 \\
\hline 13 & 88.7 & 71.6 & -18.1 & 8 & 42.6 & 94 & 51.4 \\
\hline 14 & 47.7 & 60 & 12.3 & 12 & 32.7 & 63.7 & 31 \\
\hline 15 & 48.7 & 72 & 23.3 & 6 & 44 & 66 & 22 \\
\hline 16 & 49 & 54 & 5 & 7 & 32 & 43.6 & 11.6 \\
\hline Ave & 42.3 & 47.6 & 5.25 & & 42.9 & 72.1 & 29.2 \\
\hline Std & 18.99 & 15.80 & 12.2 & & 8.03 & 20 & 17 \\
\hline & & & & & & & \\
\hline
\end{tabular}

t-Test: Two-Sample Assuming Unequal Variances

$\begin{array}{rr}\text { CONT.RTF } & \text { EXP. RTF } \\ 5.25 & 29.2 \\ 148.73733 & 288.82 \\ 16 & 16 \\ 0 & \\ 27 & \\ -4.579802 & \\ 4.71 \mathrm{E}-05 & \\ 1.7032884 & \\ 9.42 \mathrm{E}-05 & \\ 2.0518305 & \end{array}$


ORAL READING FLUENCY RESULTS OF COHEN'S D

\begin{tabular}{|c|c|c|}
\hline \multirow{2}{*}{$\begin{array}{l}\text { Mean (group } \\
1 \text { ): }\end{array}$} & 22.725 & 9 The mean \\
\hline & $\begin{array}{l}\text { for the o } \\
\text { compris }\end{array}$ & $\begin{array}{l}\text { vations that } \\
\text { oup } 1 .\end{array}$ \\
\hline \multirow{2}{*}{$\begin{array}{l}\text { Mean (group } \\
2 \text { ): }\end{array}$} & 3.168 & 9 The mean \\
\hline & $\begin{array}{l}\text { for the } \\
\text { compri }\end{array}$ & $\begin{array}{l}\text { vations that } \\
\text { oup } 2 .\end{array}$ \\
\hline \multirow{2}{*}{$\begin{array}{l}\text { Standard } \\
\text { deviation } \\
\text { (group 1): }\end{array}$} & & OSThe \\
\hline & $\begin{array}{l}\text { standard } \\
\text { observat } \\
\text { group } 1 .\end{array}$ & $\begin{array}{l}\text { iation for the } \\
\text { that comprise }\end{array}$ \\
\hline \multirow[b]{2}{*}{$\begin{array}{l}\text { Standard } \\
\text { deviation } \\
\text { (group 2): }\end{array}$} & 9.88262 & 9)The \\
\hline & $\begin{array}{l}\frac{\text { standard }}{\text { observat }} \\
\text { group } 2 .\end{array}$ & $\begin{array}{l}\text { iation for the } \\
\text { that comprise }\end{array}$ \\
\hline
\end{tabular}

Effect size (Cohen's d): 1.45489468 ORF

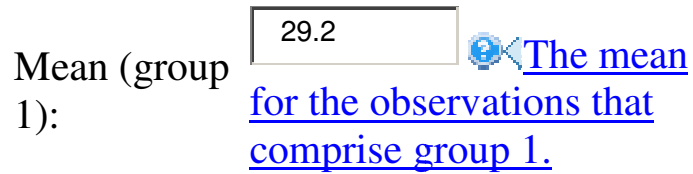

Mean (group $\longdiv { 5 . 2 5 }$ OKThe mean

2): $\quad$ for the observations that comprise group 2.

\begin{tabular}{l|l|l} 
Standard & 16.9947 & The
\end{tabular} deviation standard deviation for the (group 1): $\quad$ observations that comprise group 1.

Standard 12.1957 OKThe deviation standard deviation for the (group 2): $\quad$ observations that comprise group 2.

Effect size (Cohen's d): 1.61921391 RTF 
THE EFFICACY OF REPEATED READING 
